Article

\title{
Synthesis and Biological Evaluation of Lipophilic 1,4-Naphthoquinone Derivatives against Human Cancer Cell Lines
}

\author{
Shao-Hung Wang ${ }^{1}$, Chih-Yu Lo ${ }^{2}$, Zhong-Heng Gwo ${ }^{1}$, Hong-Jhih Lin ${ }^{1}$, Lih-Geeng Chen ${ }^{1}$, \\ Cheng-Deng Kuo ${ }^{3}$ and Jin-Yi Wu ${ }^{1, *}$
}

1 Department of Microbiology, Immunology and Biopharmaceuticals, College of Life Sciences, National Chiayi University, Chiayi 60004, Taiwan; E-Mails: shwang@mail.ncyu.edu.tw (S.-H.W.); s0990613@mail.ncyu.edu.tw (Z.-H.G.); s1030730@mail.ncyu.edu.tw (H.-J.L.); lgchen@mail.ncyu.edu.tw (L.-G.C.)

2 Department of Food Science, College of Life Sciences, National Chiayi University, Chiayi 60004, Taiwan; E-Mail: chihyulo@mail.ncyu.edu.tw

3 Department of Medical Research and Education, Taipei Veterans General Hospital, Taipei 11217, Taiwan; E-Mail: cdkuo23@gmail.com

* Author to whom correspondence should be addressed; E-Mail: jywu@mail.ncyu.edu.tw; Tel: +886-5-271-7925; Fax: +886-5-271-7778.

Academic Editors: Jean Jacques Vanden Eynde, Annie Mayence and Tien L. Huang Received: 29 May 2015 / Accepted: 25 June 2015 / Published: 30 June 2015

\begin{abstract}
To examine the effect of hydrophobicity on the anticancer activity of 1,4-naphthoquinone derivatives, a series of compounds bearing a 2-O-alkyl-, 3-C-alkyl- or 2/3- $N$-morpholinoalkyl group were synthesized and evaluated for their anticancer activity against five human cancer cell lines in vitro. The cytotoxicity of these derivatives was assayed against HT-29, SW480, HepG2, MCF-7 and HL-60 cells by the MTT assay. Among them, 2-hydroxy-3-farnesyl-1,4-naphthoquinone (11a) was found to be the most cytotoxic against these cell lines. Our results showed that the effectiveness of compound 11a may be attributed to its suppression of the survival of HT-29. Secondly, in the Hoechst 33258 staining test, compound 11a-treated cells exhibited nuclear condensation typical of apoptosis. Additionally, cell cycle analysis by flow cytometry indicated that compound 11a arrested HT-29 cells in the S phase. Furthermore, cell death detected by Annexin V-FITC/propidium iodide staining showed that compound 11a efficiently induced apoptosis of HT-29 in a
\end{abstract}


concentration-dependent manner. Taken together, compound 11a effectively inhibits colon cancer cell proliferation and may be a potent anticancer agent.

Keywords: 1,4-naphthoquinone; terpenoids; anticancer activity; human colon cancer cells HT-29; cell cycle distribution; apoptosis

\section{Introduction}

Millions of lives are lost because of cancer in the world each year and the number is increasing. However, greater than $30 \%$ of cancers are preventable [1] and some forms of cancer are curable regardless of when they are diagnosed, while many others are only curable if discovered at an early stage. Thus cancer remains a life-threatening disease and represents a serious peril to human health [2]. Chemotherapy is vital to cancer treatment and the majority of clinical antitumor agents have originated from natural products. Plants produce a wide range of secondary metabolites such as flavonoids, terpenoids, alkaloids, quinones, polyacetylene, and sugar as part of their defense mechanism against insects [3] and microbials [4]. Among these, 1,4-naphthoquinones, in particular, plumbagin (1), lawsone (2), juglone (3), and shikonin (4) [5] (Figure 1), are an important group of natural products, which have been employed in the development of potent phytochemicals because of their high abundance and relatively non-toxic nature. The 1,4-naphthoquinone pharmacophore is known to impart anticancer activity in a number of drugs, such as streptonigrin [6], mitomycins [7], and doxorubicin [8] among others. The anticancer activity of the 1,4-naphthoquinone skeleton has been the focus of recent research in the field $[9,10]$.<smiles>CC1=CC(=O)c2c(O)cccc2C1=O</smiles>

Plumbagin (1)<smiles>O=C1C=C(O)C(=O)c2ccccc21</smiles>

Lawsone (2)<smiles>O=C1C=CC(=O)c2c(O)cccc21</smiles>

Juglone (3)<smiles>CC(C)=CC[C@@H](O)C1=CC(=O)c2c(O)ccc(O)c2C1=O</smiles>

Shikonin (4)

Figure 1. Chemical structures of plumbagin (1); lawsone (2); juglone (3) and shikonin (4).

Among 1,4-naphthoquinones, there are numerous interesting biologically active compounds such as atovaquone, plumbagin, lapachol, and menadione [11]. Nevertheless, a literature precedence revealed that plumbagin (5-hydroxy-2-methyl-1,4-naphthoquinone), a wide type quinonoid, found in the plants of the Plumbaginaceae, Droseraceae, Ancestrocladceae, and Dioncophyllaceae families, possesses significant antimicrobial [12], antimalarial [13], antifilarial [14], antiprotozoal [15], anti-inflammatory [16], and anticancer properties [17-19].

Further, it was reported that monoterpenyl- and diterpenylnaphthoquinones derivatives had IC $_{50}$ values in the micromolar range against several tumor cell lines [20]. These derivatives were synthesized through Diels-Alder addition of natural terpenoids and $p$-benzoquinones, followed by side chain transformation [21]. Additionally, several 1,4-naphthoquinone derivatives incorporating with hydroxyl groups at C-5 can provide enhanced anti-proliferative activity in in vivo and in vitro [22]. 
It was also reported that 1,4-naphthoquinones interfere with the electron transport and oxidative phosphorylation processes and play roles in enzyme inhibition, and DNA cross linking as well as have antifungal, antibacterial, and anticancer activities [7]. Nonetheless, many reported amino-1,4naphthoquinones did not contain substituents on the benzene ring, although some studies [21,22] have shown that derivatives with side chains (alkyl or alkenyl) on the benzene ring considerably improved the cytotoxicity of the 1,4-naphthoquinone moiety.

In this study, we synthesized and evaluated the effect of incorporation of new alkyl or terpenyl moieties in 1,4-naphthoquinones, including lawsone substituted at the 2-C/3-O-position with alkyl or terpenyl groups and juglone substituted at position 2/3-N-morpholinoalkyl groups, with the aim to analyze the influence of these substituents on the cytotoxicity of these derivatives against human cancer cell lines. We prepared and evaluated C-2 amino substituted 1,4-naphthoquinones, a core structure present in numerous naturally occurring bioactive quinones, such as mitomycin $\mathrm{C}$, as well as some synthetic compounds [23].

\section{Results and Discussion}

\subsection{Chemistry}

In general, 1,4-naphthoquionone derivatives were synthesized from lawsone (2) with alkyl, terpenyl, alkylamino, or morpholinealkylamino moieties through 2-O- or 3-C-alkylation. As shown in Scheme 1, synthesis of 5a,b-11a,b were carried out by reacting lawsone with selected alkyl or terpenyl bromide in dimethylformamide (DMF) using triethylamine as the base and sodium iodide (NaI) as the catalyst under $\mathrm{N}_{2}$ for $1 \mathrm{~h}$ according to the reported procedure [24]. The addition of an alkyl or terpenyl group to lawsone (2) gave two products at the 2-O-postion and 3-C-position in $40.0 \%-72.3 \%$ yield. The 3-C-substituted compounds were the major products while the 2-O-substituted compounds were obtained with a yield of less than $10 \%$.

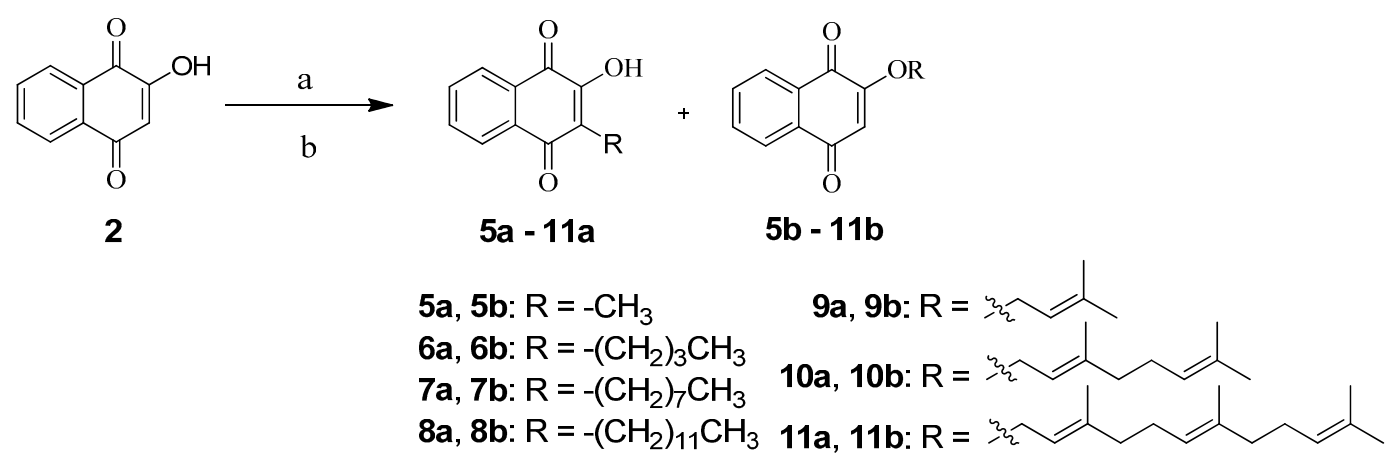

Reagents and conditions: (a) NaI, triethylamine, DMF, $\mathrm{N}_{2}, 1 \mathrm{~h}$; (b) alkyl or terpenyl bromide, $40{ }^{\circ} \mathrm{C}, 3-7$ days.

Scheme 1. Synthesis of compounds $\mathbf{5 a}, \mathbf{b}-\mathbf{1 1 a}, \mathbf{b}$.

The synthesis of juglone (3) was via oxidation of commercially available 1,5-dihydroxy-naphthalene (12) in air, and dark, in the presence of periodic acid with a yield of $67.6 \%$. Chemical transformation of juglone (3) to compounds 13a,b-19a,b was then carried out according to the reported methods with some modifications [25]. Aminated juglone (3) was prepared by stirring it with a long chain amine in ethanol for $1 \mathrm{~h}$ under reflux to give 2-alkylaminojuglone and 3-alkylaminojuglone as major and minor 
products, respectively. Lastly, once the alkylamino substituted 1,4-naphthoquinone derivatives were obtained, other alkyl- or morpholinealkylamino-juglones were prepared by adding primary alkyl amines and morpholinealkyl amines to juglone (3) in ethanolic solution at room temperature. The two-step reaction and end products are illustrated in Scheme 2.

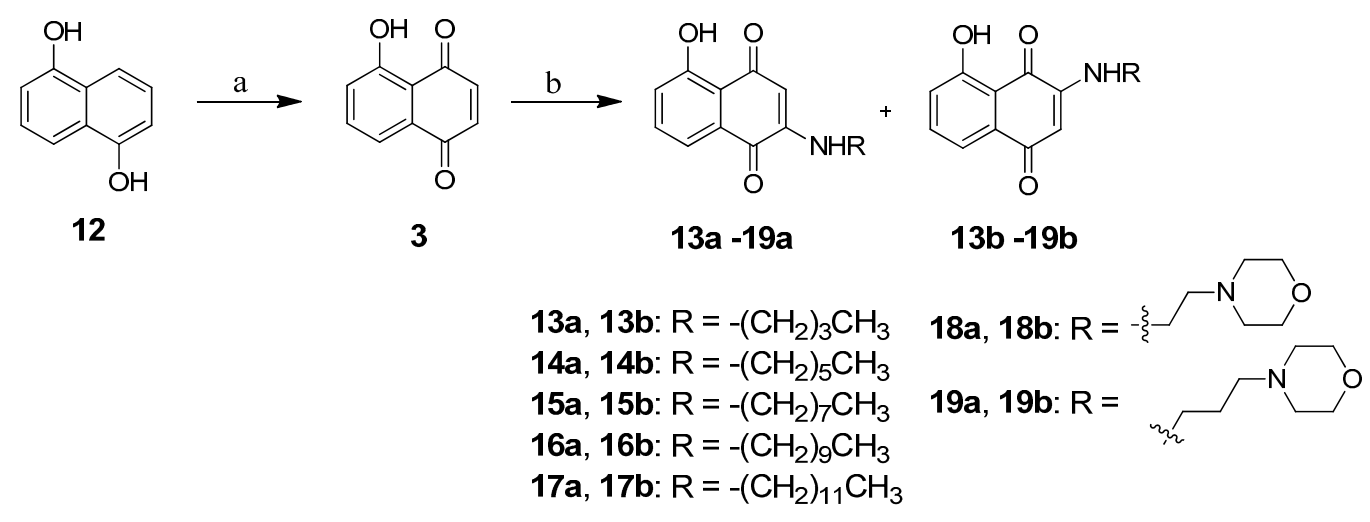

Reagents and conditions: (a) $\mathrm{HIO}_{4}$, THF/ $\mathrm{H}_{2} \mathrm{O}$, rt, 30 min; (b) alkyl amine, EtOH, reflux, 1-5 h.

Scheme 2. Synthesis of compounds 13a,b-19a,b.

\subsection{In Vitro Anti-Proliferative Activity by MTT Assay}

The cytotoxic effects of the 31 1,4-naphthoquinone derivatives were tested in vitro against five human cancer cell lines: HT29 (colorectal adenocarcinoma), SW480 (colorectal adenocarcinoma), HepG2 (hepatocellular carcinoma), HL60 (leukemia), MCF-7 (breast adenocarcinoma) and normal murine embryonic liver BNL CL.2 cells, using the 3-[4,5-dimethylthiazol-2-yl]-2,5-diphenyltetrazolium bromide (MTT) assay [26]. 5-Fluorouracil (5-Fu), cisplatin and doxorubicin were used as positive controls. The concentration (in $\mu \mathrm{M}$ ) of the test compounds which induced $50 \%$ inhibition of cell growth ( $\mathrm{IC}_{50}$ ) is shown in Table 1.

Of the 31 compounds tested, eleven compounds were bioactive and nine $(\mathbf{5 b}, \mathbf{6 b}, 7 \mathbf{b}, \mathbf{1 0 a}, \mathbf{1 1 a}, \mathbf{1 8 a}$, 18b, 19a and 19b) showed significant cell growth inhibition in four human cancer cells except MCF-7 cells. In addition, the anticancer activity of these compounds increased with the higher chain length of the terpenyl substituents, but not in long chain alkyl groups. This result suggests that the lipophilicity of terpenyl moiety of the 1,4-naphthoquinone derivatives at the 3-C-substituent affected the bioactivity of the compound (11a). In particular, among the bioactive ones, compound 11a exhibited the highest activity against the human colorectal HT-29 cell lines with an $\mathrm{IC}_{50}$ value of $1.99 \pm 0.04 \mu \mathrm{M}$ for $48 \mathrm{~h}$. Compared to plumbagin (1)'s IC 50 value of $3.67 \pm 0.46 \mu \mathrm{M}$, derivative 11a was slightly more cytotoxic against human colorectal carcinoma HT-29 cells. No significant cell death was detected in normal murine embryonic liver BNL CL.2 cells treated with plumbagin (1) and 11a. Furthermore, in BNL CL.2 cells, only a marked effect on cell death (under 20\%) was observed at the maximum concentration $(20 \mu \mathrm{M})$ of these two compounds after $48 \mathrm{~h}$ treatment (see also Figure S1). It thus appeared that both plumbagin (1) and compound 11a are cytotoxic to human colorectal cancer cells with no significant adverse side effects toward normal cells. Namely, the lipophilic characteristics of the substituent at the 3-C-position of the farnesyl moieties of 1,4-naphthoquinone derivative 11a can remarkably enhance their anticancer activity against human cancer HT-29 cell lines. In other words, a higher anticancer 
activity because the longer terpenyl moiety of the 1,4-naphthoquinone derivative 11a enhanced their cell membrane permeability and bioavailability, thus increasing their cytotoxic activities.

Table 1. $\mathrm{IC}_{50}$ values of plumbagin (1), lawsone (2) and its derivatives $\mathbf{5 a}, \mathbf{b}-\mathbf{1 1 a}, \mathbf{b}$, $\mathbf{1 3 a}, \mathbf{b}-\mathbf{1 9 a}, \mathbf{b}$ on the growth of human cancer cell lines for $48 \mathrm{~h}$.

\begin{tabular}{|c|c|c|c|c|c|c|}
\hline \multirow{2}{*}{ Compound } & \multirow{2}{*}{$\operatorname{cLog} P^{a}$} & \multicolumn{5}{|c|}{$\mathrm{IC}_{50}(\mu \mathrm{M})^{\mathrm{b}}($ Mean $\pm \mathrm{SD})$} \\
\hline & & HT-29 Colon & SW480 Colon & HepG2 Liver & HL60 Leukemia & MCF-7 Breast \\
\hline Plumbagin (1) & 2.78 & $3.67 \pm 0.46$ & $2.19 \pm 0.65$ & $2.32 \pm 0.18$ & $5.90 \pm 1.21$ & $20.89 \pm 0.70$ \\
\hline Lawsone (2) & 1.68 & $>100$ & $>100$ & $>100$ & $45.12 \pm 7.90$ & $>100$ \\
\hline Juglone (3) & 2.26 & $>50$ & $>50$ & $>50$ & $46.95 \pm 0.58$ & $>50$ \\
\hline $5 \mathbf{a}$ & 2.19 & $>100$ & $97.09 \pm 2.36$ & $94.08 \pm 2.63$ & $>100$ & $>100$ \\
\hline $5 \mathbf{b}$ & 1.78 & $8.16 \pm 1.16$ & $4.23 \pm 0.50$ & $3.32 \pm 0.66$ & $16.40 \pm 2.84$ & $>25$ \\
\hline $6 \mathbf{a}$ & 3.79 & $>100$ & $>100$ & $>100$ & $>100$ & $>100$ \\
\hline $6 b$ & 3.22 & $14.81 \pm 0.65$ & $2.02 \pm 0.20$ & $3.67 \pm 0.84$ & $20.04 \pm 0.79$ & $31.03 \pm 0.32$ \\
\hline $7 \mathbf{a}$ & 5.90 & $33.44 \pm 1.48$ & $9.73 \pm 0.04$ & $20.20 \pm 3.52$ & $>100$ & $>50$ \\
\hline $7 \mathbf{b}$ & 5.34 & $28.01 \pm 3.52$ & $8.51 \pm 0.53$ & $9.66 \pm 0.50$ & $23.42 \pm 1.24$ & $20.81 \pm 3.67$ \\
\hline $8 \mathbf{a}$ & 7.46 & $>25$ & $>25$ & $>25$ & $>25$ & $>25$ \\
\hline $8 b$ & 8.02 & $>25$ & $>25$ & $>25$ & $>25$ & $>25$ \\
\hline $9 a$ & 3.70 & $>100$ & $>100$ & $74.18 \pm 2.61$ & $>100$ & $>100$ \\
\hline $9 \mathbf{b}$ & 3.34 & $>50$ & $20.72 \pm 1.19$ & $35.56 \pm 1.13$ & $>50$ & $>50$ \\
\hline $10 \mathbf{a}$ & 5.73 & $12.90 \pm 2.13$ & $14.14 \pm 0.96$ & $19.10 \pm 0.26$ & $9.12 \pm 0.69$ & $>100$ \\
\hline $10 b$ & 5.37 & $42.90 \pm 1.13$ & $44.23 \pm 1.06$ & $29.10 \pm 1.21$ & $29.56 \pm 0.88$ & $>100$ \\
\hline $11 \mathrm{a}$ & 6.82 & $1.99 \pm 0.04$ & $2.02 \pm 0.31$ & $14.01 \pm 2.70$ & $5.41 \pm 0.88$ & $47.01 \pm 0.47$ \\
\hline $11 b$ & 7.40 & $40.37 \pm 0.75$ & $37.16 \pm 2.21$ & $32.33 \pm 1.46$ & $35.10 \pm 1.52$ & $>100$ \\
\hline $13 \mathbf{a}$ & 3.65 & $9.82 \pm 1.51$ & $16.17 \pm 0.72$ & $9.39 \pm 0.12$ & $45.69 \pm 2.48$ & $>100$ \\
\hline $13 b$ & 3.65 & $18.11 \pm 1.68$ & $8.28 \pm 0.12$ & $17.89 \pm 0.14$ & $6.50 \pm 0.32$ & $23.71 \pm 0.82$ \\
\hline $14 a$ & 4.99 & $>50$ & $>50$ & $>50$ & $>50$ & $>50$ \\
\hline $14 b$ & 4.99 & $34.53 \pm 1.20$ & $15.13 \pm 0.49$ & $17.82 \pm 2.29$ & $>50$ & $>50$ \\
\hline $15 \mathbf{a}$ & 6.05 & $>50$ & $>50$ & $>50$ & $>50$ & $>50$ \\
\hline $15 b$ & 6.05 & $>50$ & $20.23 \pm 2.18$ & $47.06 \pm 0.63$ & $>50$ & $>50$ \\
\hline $16 a$ & 7.11 & $>50$ & $>50$ & $>50$ & $>50$ & $>50$ \\
\hline $16 b$ & 7.11 & $>50$ & $>50$ & $>50$ & $>50$ & $>50$ \\
\hline $17 \mathbf{a}$ & 8.17 & $>20$ & $>20$ & $>20$ & $>20$ & $>20$ \\
\hline $17 b$ & 8.17 & $>20$ & $>20$ & $>20$ & $>20$ & $>20$ \\
\hline $18 \mathbf{a}$ & 2.51 & $9.42 \pm 0.45$ & $8.86 \pm 0.50$ & $11.72 \pm 0.42$ & $8.42 \pm 0.86$ & $>50$ \\
\hline $18 b$ & 2.51 & $8.59 \pm 0.67$ & $5.19 \pm 0.44$ & $8.84 \pm 0.07$ & $6.49 \pm 0.84$ & $>50$ \\
\hline $19 a$ & 2.80 & $9.44 \pm 0.32$ & $4.66 \pm 0.25$ & $10.08 \pm 0.57$ & $6.35 \pm 0.24$ & $>50$ \\
\hline $19 b$ & 2.80 & $11.38 \pm 1.51$ & $3.86 \pm 0.61$ & $7.90 \pm 0.16$ & $7.76 \pm 0.54$ & $>50$ \\
\hline Cisplatin & - & $24.07 \pm 0.03$ & $40.72 \pm 1.18$ & $36.07 \pm 3.11$ & $>100$ & $>100$ \\
\hline $5-\mathrm{Fu}$ & - & $>100$ & $32.72 \pm 8.32$ & $40.18 \pm 7.63$ & $>100$ & $>100$ \\
\hline Doxorubicin & - & $1.70 \pm 0.20$ & $0.53 \pm 0.07$ & $0.30 \pm 0.02$ & $14.26 \pm 0.89$ & $0.39 \pm 0.06$ \\
\hline
\end{tabular}

${ }^{\mathrm{a}}$ Calculated $\log$ value of partition coefficient by ChemDraw Ultra 8.0; ${ }^{\mathrm{b}} \mathrm{IC}_{50}=$ compound concentration required to inhibit tumor cell proliferation by $50 \%$. Data are expressed as the mean $\pm \mathrm{SD}$ from the dose response curves of at least three independent experiments. 


\subsection{Cytotoxic Activity of Plumbagin (1) and Compound 11a was Exhibited in a Time-Dependent Manner}

In light of the cytotoxicity findings described above, we extended our study on the anti-proliferation efficacy of plumbagin (1) and lawsone derivative 11a against HT-29 cells to $24 \mathrm{~h}, 48 \mathrm{~h}$ and $72 \mathrm{~h}$ periods. The data on plumbagin (1) was used here as base case. As shown in Table 2, first of all, the cytotoxicity of compound 11a demonstrated, once again stronger bioactivity than that of plumbagin (1) in vitro. In addition, the growth inhibition of HT-29 cells induced by these two samples was in a time-dependent manner. The IC50 values of plumbagin (1) and 11a in HT-29 cells for $24 \mathrm{~h}, 48 \mathrm{~h}$ and $72 \mathrm{~h}$ incubation times were $4.72,3.67,2.10 \mu \mathrm{M}$ and $>20,1.99,0.84 \mu \mathrm{M}$, respectively. The results revealed that plumbagin (1) and 11a inhibited the cell viability of HT-29 cells in a time-dependent manner at longer time.

Table 2. Cytotoxicity of plumbagin (1) and 11a on HT-29 for 24 h, 48 h, and $72 \mathrm{~h}$.

\begin{tabular}{cccc}
\hline \multirow{2}{*}{ Compound } & \multicolumn{3}{c}{ IC $_{\mathbf{5 0}}(\boldsymbol{\mu M})^{\mathbf{a}}($ Mean $\pm \mathbf{S D})$} \\
\cline { 2 - 4 } & $\mathbf{2 4} \mathbf{~ h}$ & $\mathbf{4 8} \mathbf{~ h}$ & $\mathbf{7 2} \mathbf{~ h}$ \\
\hline Plumbagin (1) & $4.72 \pm 0.07$ & $3.67 \pm 0.46$ & $2.10 \pm 0.23$ \\
11a & $>20$ & $1.99 \pm 0.04$ & $0.84 \pm 0.12$ \\
\hline
\end{tabular}

${ }^{\text {a }} \mathrm{IC}_{50}=$ compound concentration required to inhibit tumor cell proliferation by $50 \%$. Data are expressed as the mean \pm SD from the dose response curves of at least three independent experiments.

\subsection{Nuclear Morphological Changes of HT-29 Cells Treated with Plumbagin (1) and Compound 11a}

Apoptosis, shown by morphological changes, were detected through Hoechst 33258 staining in the HT-29 cells. The classical characteristics of apoptotic cells are chromatin condensation and nuclear fragmentation [27]. To further investigate the role apoptosis plays in the superior cytotoxicity of plumbagin (1) and the potent compound 11a, we incubated HT-29 cells, with plumbagin (1) and 11a, separately, for $48 \mathrm{~h}$. The cells were then stained with Hoechst 33258, and examined by fluorescence microscopy for topical morphological changes. As shown in Figure 2, while the nuclei of the cells were round in shape and stained homogenously in the control without testing compound, those treated with plumbagin (1) and 11a showed typical morphological features of apoptotic cells based on cell shrinkage, chromatin condensation and nuclear fragmentation [28]. Evidently, the proliferation of the cancer cell is inhibited by the testing compounds in vitro.

A

Concentration $(\mu \mathrm{M})$

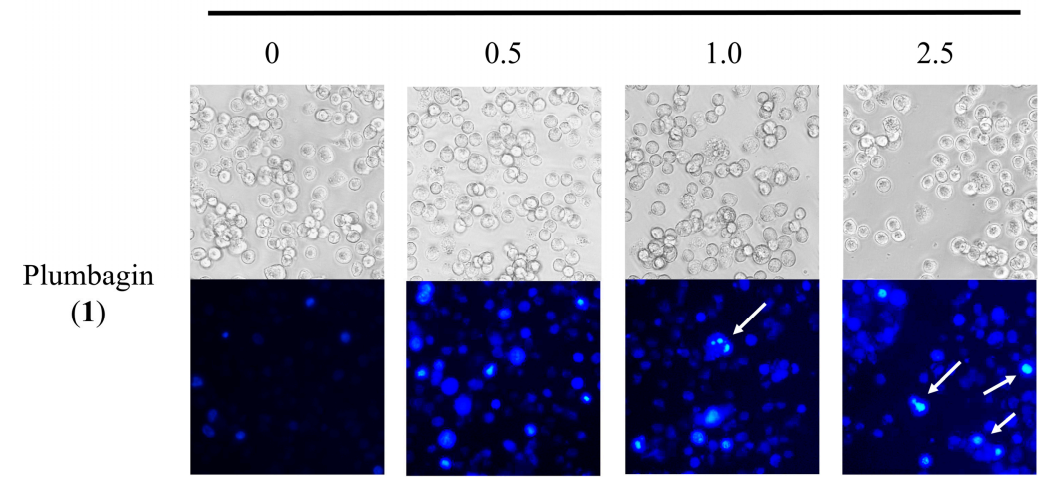

Figure 2. Cont. 
B Concentration $(\mu \mathrm{M})$

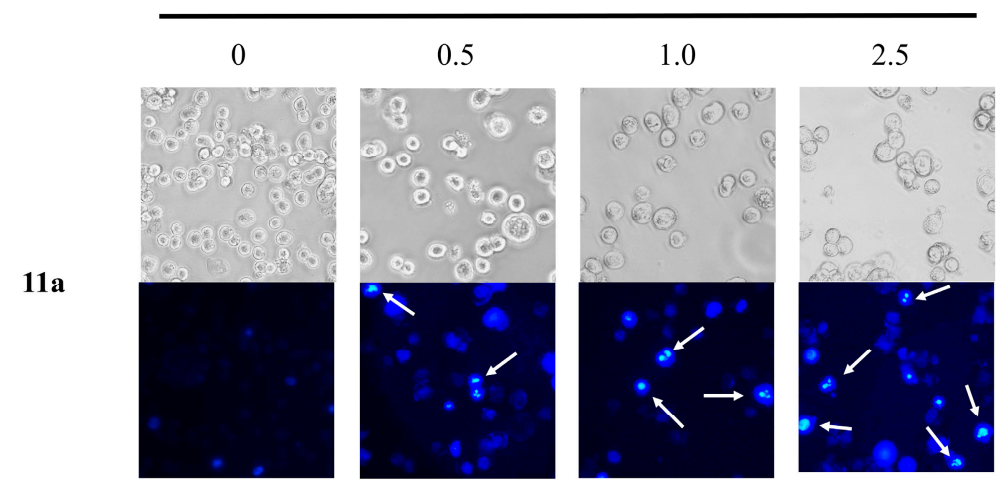

Figure 2. The morphological changes of HT-29 cells treated with 0-2.5 $\mu \mathrm{M}$ plumbagin (1) (A) and 11a (B) for 48 h. (magnification, 200×). (A,B) The upper panels showed the cell morphology under phase-contrast microscopy, and the lower panels display the Hoechst 33258-stained nuclear patterns take by fluorescence microscopy (magnification, 200×).

\subsection{Cell Cycle Distribution Analysis Using Flow Cytometry}

To probe the apoptotic effects of plumbagin (1) and 11a on cell cycle progression, HT-29 cells were treated once again with these compounds, separately, at different concentrations for $48 \mathrm{~h}$. The cell cycle distribution of the cancer cells was analyzed by flow cytometry, and the sub-G1 phase analyzed by flow cytometry with propidium iodide (PI) staining [28]. The control of the experiment was the untreated cells. As illustrated in Figure 3, only a small fraction of apoptotic cells $(0.8 \%)$ was detected in the control as well as in plumbagin (1) at a low concentration of $2.5 \mu \mathrm{M}$. However, as plumbagin (1) dosage increased from 0.5 to $2.5 \mu \mathrm{M}$, the fraction of apoptotic cell went up substantially from $4.5 \%$ to $7.6 \%$ in a concentration-dependent manner. As for compound 11a, the apoptotic effect meagerly laid between $10.7 \%$ to $27.8 \%$ across the treatment range of $0.5-2.5 \mu \mathrm{M}$ and induced cell accumulation in the $\mathrm{S}$ phase.

A Concentration $(\mu \mathrm{M})$

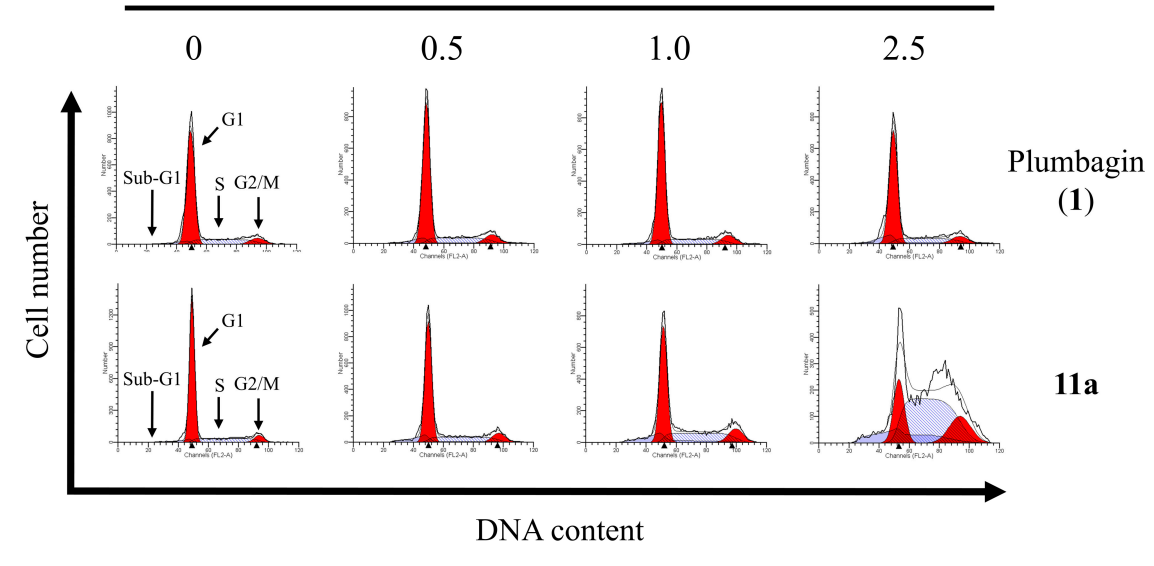

Figure 3. Cont. 

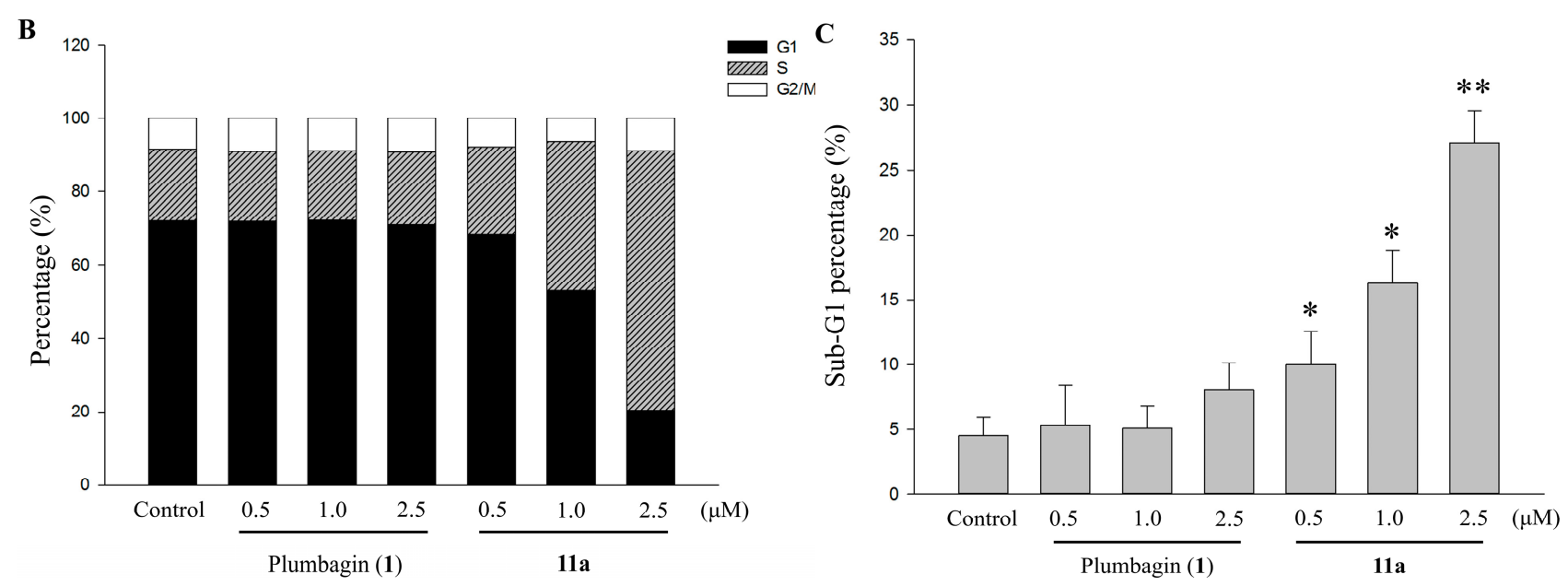

Figure 3. (A) The effects of the $48 \mathrm{~h}$ treatments with $0-2.5 \mu \mathrm{M}$ plumbagin (1) and 11a on cell cycle distribution of HT-29. After treatment, cells were fixed and stained with PI, and the cell cycle distribution was examined by flow cytometry; (B) Quantitative data of cell cycle analysis of HT-29 treated with 0-2.5 $\mu \mathrm{M}$ plumbagin (1) and 11a for $48 \mathrm{~h}$; (C) Compared with control, the treated with plumbagin (1) and 11a shows the obvious increase in sub-G1 fraction. Each value represents the mean $\pm \mathrm{SD}$ of three independent experiments. $* p<0.05, * * p<0.01$ vs. control.

\subsection{Apoptotic Analyses-Annexin V-FITC/PI Double Staining and Flow Cytometry Analyses}

Quantitative analysis of apoptotic effects of plumbagin (1) and 11a on HT-29 cells was conducted by flow cytometry using Annexin V-FITC and PI double staining. This was to study in depth the bioactivities of plumbagin (1) and 11a against HT-29 cells. Thus, the cancer cells were treated with vehicle alone as control or with one of the two testing compounds at different concentrations $(0.5-2.5 \mu \mathrm{M})$. After $48 \mathrm{~h}$, the samples were double-stained with Annexin V-FITC and PI [29]. The percentages of cell populations at various stages of apoptosis were exhibited in Figure 4. The total apoptosis rates were $1.08 \%, 8.65 \%, 13.21 \%$, and $21.02 \%$ at concentrations of $0,0.5,1.0$, and $2.5 \mu \mathrm{M}$ of compound 11a, respectively. Though the data pointed out that the distributions of apoptotic cell death resulting from the treatment of lawsone derivative 11a were concentration-dependent, this was not the case for plumbagin (1). Starting from a dosage of $0.5 \mu \mathrm{M}$, compound 11a induced higher frequency of HT-29 cells apoptosis, as well as cytotoxic effects at both early and late stages. For plumbagin (1) though, the only discernible effect was seen at a higher threshold $(2.5 \mu \mathrm{M})$. We attribute this finding to and confirmed that the superior efficiency of lawsone derivative 11a in its cytotoxicity and inhibitive function on human colorectal cell proliferation. 
A

Concentration $(\mu \mathrm{M})$

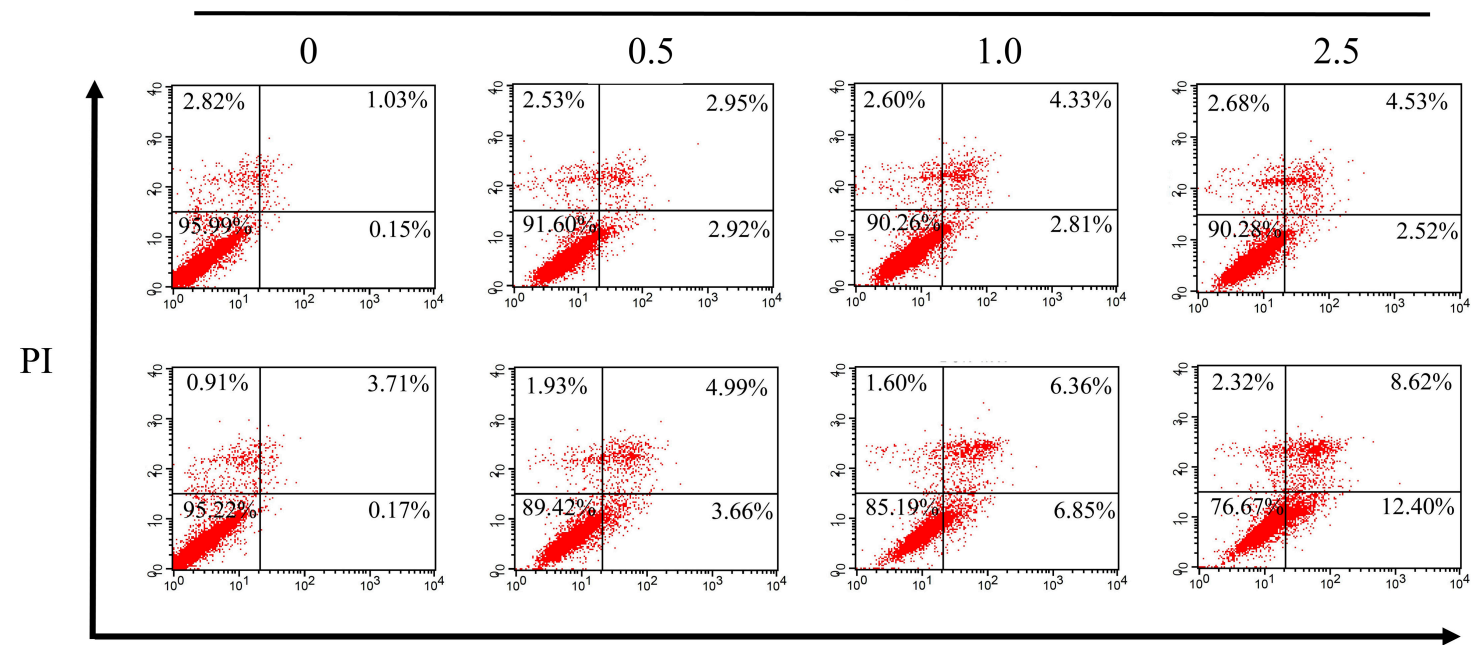

Plumbagin

(1)

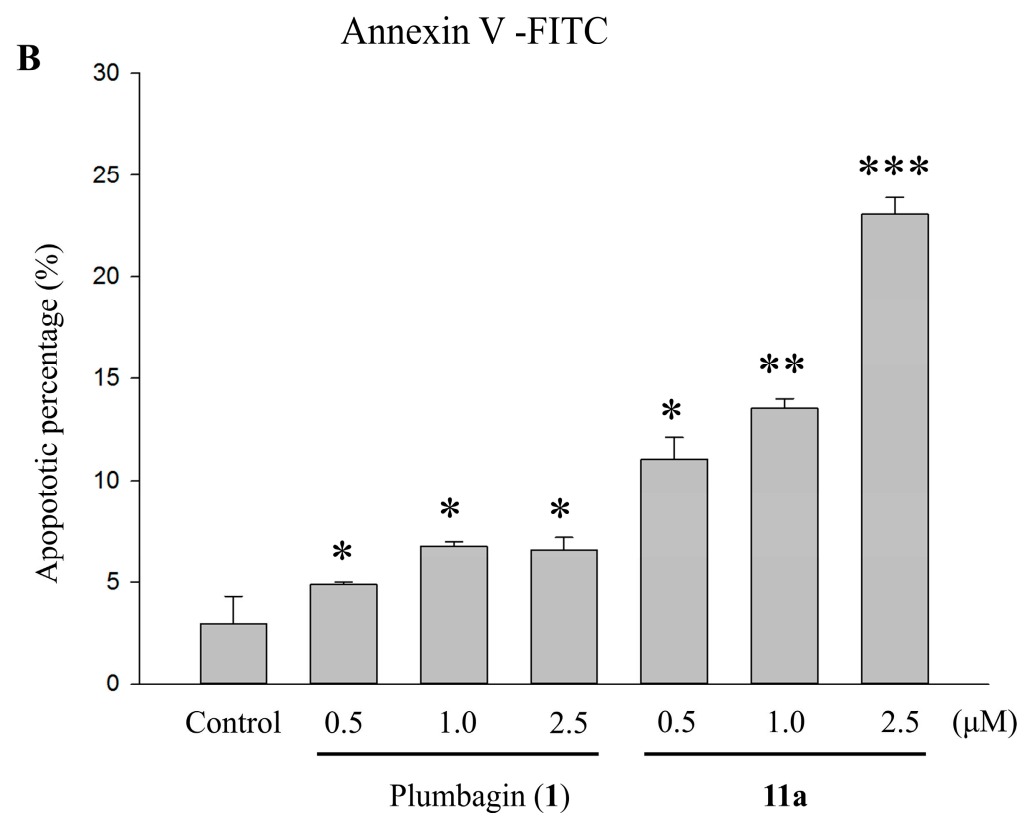

Figure 4. (A) The effects of the $48 \mathrm{~h}$ treatments with $0-2.5 \mu \mathrm{M}$ plumbagin (1) and 11a on apoptotic percentage distribution of HT-29 cells by Annexin V-FITC/PI staining. (B) The apoptosis rate was calculated by flow cytometry and cell apoptosis was defined in early and late apoptosis treatment with $0-2.5 \mu \mathrm{M}$ plumbagin (1) and 11a for $48 \mathrm{~h}$. Each value represents the mean $\pm \mathrm{SD}$ of three independent experiments. ${ }^{*} p<0.05$, ** $p<0.01$ and $* * * p<0.001$ vs. control.

\section{Experimental Section}

\subsection{General}

All chemical reagents of commercial quality were used as received (Sigma-Aldrich, St. Louis, MO, USA) and were used without further purification. Solvents were dried and the synthesized compounds were purified using standard techniques. The progression of reactions was monitored by TLC on aluminum plates coated with silica gel with a fluorescent indicator (Merck, Darmstadt, Germany) unless otherwise stated. Melting points were determined using open capillaries using the Fargo MP-2D 
apparatus (Prosperous instrument, Chaiyi, Taiwan, ROC) and are reported uncorrected. NMR spectra were recorded using TMS as an internal standard in $\mathrm{CDCl}_{3}$ at $500 \mathrm{MHz}$ for ${ }^{1} \mathrm{H}$ and at $125 \mathrm{MHz}$ for ${ }^{13} \mathrm{C}$ (Bruker Biospin GmbH AVANCE III $500 \mathrm{MHz}$, Rheinstetten, Germany). The mass spectra were acquired using a Thermo Finnigan model LXQ (Thermo Electron Co., Waltham, MA, USA) ion trap mass spectrometer equipped with ESI source interference and controlled by Xcalibur 2.06 (Thermo Electron Co., Waltham, MA, USA). The mass spectra were acquired in a positive ion mode or a negative ion mode. ESI high-resolution mass spectra (HRMS) were recorded on a Finnigan MAT 95S mass spectrometry (Thermo Fisher Scientific Co. Ltd., Waltham, MA, USA). Column chromatography was performed with silica gel SiliaFlash ${ }^{\circledR}$ G60 (60-200 $\mu \mathrm{m}$, Quebec City, QC, Canada) purchased from SiliCycle Inc. (Quebec City, QC, Canada). In general, the reactions were carried out under anhydrous conditions in dry solvent and nitrogen atmosphere. The purity of the compounds was more than $98 \%$ based on the analysis of HPLC (Hitachi High-Technologies, Tokyo, Japan) using a RP-C 18 column (4.6 mm $\times 250 \mathrm{~mm}, 5 \mu \mathrm{m}$, Merck, Darmstadt, Germany).

\subsection{General Synthetic Procedure for $\mathbf{5 a}, \mathbf{b}-\mathbf{1 1 a}, \mathbf{b}$}

A mixture of lawsone $(2.87 \mathrm{mmol}), \mathrm{NaI}(3.16 \mathrm{mmol})$, triethylamine $(3.16 \mathrm{mmol})$ and alkyl or terpenyl bromide $(2.87 \mathrm{mmol})$ were stirred in DMF $(5 \mathrm{~mL})$ at $40{ }^{\circ} \mathrm{C}$ for three days. After the reaction was cooled to room temperature, $1 \mathrm{~N} \mathrm{HCl}$ was added and the solution was poured into a separatory funnel with water, dichloromethane was added and the organic layer was separated from the aqueous layer. The organic layer was collected, dried over anhydrous magnesium sulfate $\left(\mathrm{MgSO}_{4}\right)$ and concentrated under reduced pressure to remove the solvent, and then was subjected to column chromatography (ethyl acetate/ $n$-hexane $=1 / 7$ ) to produce yellow solid compounds, which were purified by recrystallization from $n$-hexane.

2-Hydroxy-3-methyl-1,4-naphthoquinone (5a). The reaction produced 5a in $45.3 \%$ as a yellow solid; mp 173.4-174.1 ${ }^{\circ} \mathrm{C}$ (lit. [30] 173-174 ${ }^{\circ} \mathrm{C}$ ). ${ }^{1} \mathrm{H}-\mathrm{NMR}\left(500 \mathrm{MHz}, \mathrm{CDCl}_{3}\right) \delta_{\mathrm{H}} 2.09$ (s, 3H, $\left.\mathrm{CH}_{3}\right), 7.29$ (bs, $1 \mathrm{H}, 2-\mathrm{OH}), 7.66$ (dt, $J=1.2,7.5 \mathrm{~Hz}, 1 \mathrm{H}, \mathrm{H}-7), 7.73$ (dt, $J=1.4,7.6 \mathrm{~Hz}, 1 \mathrm{H}, \mathrm{H}-6), 8.06$ (dd, $J=1.2$, $7.7 \mathrm{~Hz}, 1 \mathrm{H}, \mathrm{H}-8), 8.10(\mathrm{dd}, J=0.7,7.7 \mathrm{~Hz}, 1 \mathrm{H}, \mathrm{H}-5) ;{ }^{13} \mathrm{C}-\mathrm{NMR}\left(125 \mathrm{MHz}, \mathrm{CDCl}_{3}\right) \delta_{\mathrm{C}} 8.91\left(\mathrm{CH}_{3}\right)$, 120.75 (C-3), 126.36 (C-8), 126.97 (C-5), 129.64 (C-9), 133.13 (C-6), 132.94 (C-10), 134.83 (C-7), $153.13(\mathrm{C}-2) 181.19(\mathrm{C}=\mathrm{O}), 185.02(\mathrm{C}=\mathrm{O})$; LC-MS $\left(\mathrm{ESI}^{-}, \mathrm{m} / \mathrm{z}\right)$ calculated for $\mathrm{C}_{11} \mathrm{H}_{8} \mathrm{O}_{3}$ : 188.05 , found for $186.98[\mathrm{M}-\mathrm{H}]^{-}$; HRMS-ESI: $m / z$ calculated for $\mathrm{C}_{11} \mathrm{H}_{8} \mathrm{O}_{3}: 188.0473[\mathrm{M}]^{+}$, found for 188.0471 .

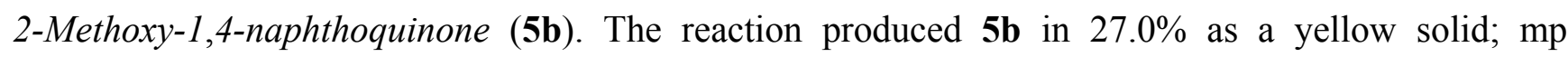
187.0-187.8 ${ }^{\circ} \mathrm{C}$ (lit. [31] 186-189 $\left.{ }^{\circ} \mathrm{C}\right) .{ }^{1} \mathrm{H}-\mathrm{NMR}\left(500 \mathrm{MHz}, \mathrm{CDCl}_{3}\right) \delta_{\mathrm{H}} 3.89\left(\mathrm{~s}, 3 \mathrm{H}, \mathrm{CH}_{3}\right), 6.16(\mathrm{~s}, 1 \mathrm{H}$, H-3), 7.70 (dt, $J=1.3,7.5 \mathrm{~Hz}, 1 \mathrm{H}, \mathrm{H}-7), 7.74$ (dt, $J=1.3,7.5 \mathrm{~Hz}, 1 \mathrm{H}, \mathrm{H}-6), 8.07$ (dd, $J=1.2,7.5 \mathrm{~Hz}$, $1 \mathrm{H}, \mathrm{H}-8), 8.11(\mathrm{dd}, J=1.2,7.5 \mathrm{~Hz}, 1 \mathrm{H}, \mathrm{H}-5) ;{ }^{13} \mathrm{C}-\mathrm{NMR}\left(125 \mathrm{MHz}, \mathrm{CDCl}_{3}\right) \delta_{\mathrm{C}} 56.65\left(\mathrm{CH}_{3}\right), 110.14(\mathrm{C}-3)$, 126.43 (C-8), 126.96 (C-5), 131.29 (C-9), 132.28 (C-10), 133.58 (C-6), 134.57 (C-7), 160.67 (C-2), $180.36(\mathrm{C}=\mathrm{O}), 185.08(\mathrm{C}=\mathrm{O})$; LC-MS $\left(\mathrm{ESI}^{+}, \mathrm{m} / \mathrm{z}\right)$ calculated for $\mathrm{C}_{11} \mathrm{H}_{8} \mathrm{O}_{3}$ : 188.05, found for 189.09 $[\mathrm{M}+\mathrm{H}]^{+}$; HRMS-ESI: $m / z$ calculated for $\mathrm{C}_{11} \mathrm{H}_{8} \mathrm{O}_{3}: 188.0473[\mathrm{M}]^{+}$, found for 188.0476 .

2-Hydroxy-3-butyl-1,4-naphthoquinone (6a). The reaction produced $\mathbf{6 a}$ in $36.6 \%$ as a yellow solid; $\mathrm{mp}$ 97.1-98.0 ${ }^{\circ} \mathrm{C}$ (lit. [32] 93-94 $\left.{ }^{\circ} \mathrm{C}\right) .{ }^{1} \mathrm{H}-\mathrm{NMR}\left(500 \mathrm{MHz}, \mathrm{CDCl}_{3}\right) \delta_{\mathrm{H}} 0.92\left(\mathrm{t}, J=7.5 \mathrm{~Hz}, 3 \mathrm{H}, \mathrm{CH}_{3}\right), 1.39$ 
(p, $\left.J=7.5 \mathrm{~Hz} 2 \mathrm{H}, \mathrm{H}-3^{\prime}\right), 1.50$ (p, $\left.J=7.5 \mathrm{~Hz}, 2 \mathrm{H}, \mathrm{H}-2^{\prime}\right), 2.58$ (t, $\left.J=7.5 \mathrm{~Hz}, 2 \mathrm{H}, \mathrm{H}-1^{\prime}\right), 7.30$ (s, 1H, 2-OH), 7.65 (t, $J=7.5 \mathrm{~Hz}, 1 \mathrm{H}, \mathrm{H}-7), 7.73$ (t, $J=7.5 \mathrm{~Hz}, 1 \mathrm{H}, \mathrm{H}-6), 8.05$ (d, $J=7.5 \mathrm{~Hz}, 1 \mathrm{H}, \mathrm{H}-8), 8.10$ $(\mathrm{d}, J=7.5 \mathrm{~Hz}, 1 \mathrm{H}, \mathrm{H}-5) ;{ }^{13} \mathrm{C}-\mathrm{NMR}\left(125 \mathrm{MHz}, \mathrm{CDCl}_{3}\right) \delta \mathrm{c} 14.12\left(\mathrm{CH}_{3}\right), 23.09\left(\mathrm{C}-1^{\prime}\right), 29.91\left(\mathrm{C}-3^{\prime}\right)$, 30.64 (C-2'), 125.04 (C-3), 126.26 (C-8), 126.99 (C-5), 129.67 (C-9), 133.06 (C-6), 133.18 (C-10), 135.04 (C-7), $153.23(\mathrm{C}-2), 181.70(\mathrm{C}=\mathrm{O}), 184.96(\mathrm{C}=\mathrm{O})$; LC-MS $\left(\mathrm{ESI}^{-}, \mathrm{m} / \mathrm{z}\right)$ calculated for $\mathrm{C}_{14} \mathrm{H}_{14} \mathrm{O}_{3}$ : 230.09, found for 229.05 [M - H] $]^{-}$; HRMS-ESI: $m / z$ calculated for $\mathrm{C}_{14} \mathrm{H}_{14} \mathrm{O}_{3}: 230.0943[\mathrm{M}]^{+}$, found for 230.0948 .

2-Butyloxy-1,4-naphthoquinone (6b). The reaction produced $\mathbf{6 b}$ in $5.5 \%$ as a yellow solid; $\mathrm{mp}$ 111.5-112.1 ${ }^{\circ} \mathrm{C}$ (lit. [33] 97-98 ${ }^{\circ} \mathrm{C}$ ). ${ }^{1} \mathrm{H}-\mathrm{NMR}\left(500 \mathrm{MHz}, \mathrm{CDCl}_{3}\right) \delta \mathrm{H} 0.99$ (t, $\left.J=7.4 \mathrm{~Hz}, 3 \mathrm{H}, \mathrm{CH}_{3}\right)$, 1.53 (p, $\left.J=7.5 \mathrm{~Hz} 2 \mathrm{H}, \mathrm{H}-3^{\prime}\right), 1.88$ (p, $\left.J=7.1 \mathrm{~Hz}, 2 \mathrm{H}, \mathrm{H}-2^{\prime}\right), 4.02$ (t, $\left.J=6.6 \mathrm{~Hz}, 2 \mathrm{H}, \mathrm{H}-1^{\prime}\right), 6.16$ (s, 1H, H-3), 7.70 (dt, $J=1.0,7.5 \mathrm{~Hz}, 1 \mathrm{H}, \mathrm{H}-7), 7.74$ (dt, $J=1.0,7.5 \mathrm{~Hz}, 1 \mathrm{H}, \mathrm{H}-6), 8.07$ (d, $J=7.3 \mathrm{~Hz}, 1 \mathrm{H}$, $\mathrm{H}-8), 8.11(\mathrm{~d}, J=7.3 \mathrm{~Hz}, 1 \mathrm{H}, \mathrm{H}-5) ;{ }^{13} \mathrm{C}-\mathrm{NMR}\left(125 \mathrm{MHz}, \mathrm{CDCl}_{3}\right) \delta_{\mathrm{c}} 13.70\left(\mathrm{CH}_{3}\right), 19.13\left(\mathrm{C}-3^{\prime}\right), 30.25$ (C-2'), 69.39 (C-1'), 110.19 (C-3), 126.11 (C-8), 126.68 (C-5), 131.20 (C-9), 132.04 (C-10), 133.26 (C-6), $134.21(\mathrm{C}-7), 159.93(\mathrm{C}-2), 180.18(\mathrm{C}=\mathrm{O}), 185.10(\mathrm{C}=\mathrm{O})$; LC-MS $\left(\mathrm{ESI}^{-}, \mathrm{m} / z\right)$ calculated for $\mathrm{C}_{14} \mathrm{H}_{14} \mathrm{O}_{3}$ : 230.09, found for $229.52[\mathrm{M}-\mathrm{H}]^{-}$; HRMS-ESI: $m / z$ calculated for $\mathrm{C}_{14} \mathrm{H}_{14} \mathrm{O}_{3}: 230.0943[\mathrm{M}]^{+}$, found for 230.0941 .

2-Hydroxy-3-octyl-1,4-naphthoquinone (7a). The reaction produced $7 \mathbf{a}$ in $36.2 \%$ as a yellow solid; $\mathrm{mp}$ 91.1-91.6 ${ }^{\circ} \mathrm{C}$ (lit. [34] 88-89 ${ }^{\circ} \mathrm{C}$ ). ${ }^{1} \mathrm{H}-\mathrm{NMR}\left(500 \mathrm{MHz}, \mathrm{CDCl}_{3}\right) \delta_{\mathrm{H}} 0.86\left(\mathrm{t}, J=7.5 \mathrm{~Hz}, 3 \mathrm{H}, \mathrm{CH}_{3}\right)$, 1.23-1.36 (m, 8H, H-4', H-5', H-6', H-7'), 1.39 (p, J=8.0 Hz, 2H, H-3'), 1.51 (p, J= 7.6 Hz, 2H, H-2'), $2.58\left(\mathrm{t}, J=7.7 \mathrm{~Hz}, 2 \mathrm{H}, \mathrm{H}-1^{\prime}\right), 7.26(\mathrm{~s}, 1 \mathrm{H}, 2-\mathrm{OH}), 7.66$ (dt, $\left.J=1.0,7.6 \mathrm{~Hz}, 1 \mathrm{H}, \mathrm{H}-7\right), 7.73$ (dt, $J=1.0$, $7.6 \mathrm{~Hz}, 1 \mathrm{H}, \mathrm{H}-6), 8.05$ (d, $J=7.5 \mathrm{~Hz}, 1 \mathrm{H}, \mathrm{H}-8), 8.10$ (d, $J=7.6 \mathrm{~Hz}, 1 \mathrm{H}, \mathrm{H}-5) ;{ }^{13} \mathrm{C}-\mathrm{NMR}(125 \mathrm{MHz}$, $\left.\mathrm{CDCl}_{3}\right) \delta_{\mathrm{c}} 14.32\left(\mathrm{CH}_{3}\right), 22.88\left(\mathrm{C}-1^{\prime}\right), 28.53\left(\mathrm{C}-7^{\prime}\right), 29.46\left(\mathrm{C}-2^{\prime}\right), 29.64\left(\mathrm{C}-3^{\prime}\right), 29.92\left(\mathrm{C}-4^{\prime}\right), 30.41\left(\mathrm{C}-5^{\prime}\right)$, 32.10 (C-6'), 125.09 (C-3), 126.27 (C-8), 127.01 (C-5), 129.69 (C-9), 133.06 (C-6), 133.21 (C-10), $135.04(\mathrm{C}-7), 153.20(\mathrm{C}-2), 181.72(\mathrm{C}=\mathrm{O}), 184.94(\mathrm{C}=\mathrm{O})$; LC-MS $\left(\mathrm{ESI}^{+}, m / z\right)$ calculated for $\mathrm{C}_{18} \mathrm{H}_{22} \mathrm{O}_{3}$ : 286.16, found for $309.35[\mathrm{M}+\mathrm{Na}]^{+}$; HRMS-ESI: $m / z$ calculated for $\mathrm{C}_{18} \mathrm{H}_{22} \mathrm{O}_{3}: 286.1569[\mathrm{M}]^{+}$, found for 286.1568 .

2-Octyloxy-1,4-naphthoquinone (7b). The reaction produced $\mathbf{7 b}$ in $3.8 \%$ as a yellow solid; $\mathrm{mp}$ 94.1-95.8 ${ }^{\circ} \mathrm{C} .{ }^{1} \mathrm{H}-\mathrm{NMR}\left(500 \mathrm{MHz}, \mathrm{CDCl}_{3}\right) \delta_{\mathrm{H}} 0.86\left(\mathrm{t}, J=6.9,3 \mathrm{H}, \mathrm{CH}_{3}\right), 1.23-1.35$ (m, 8H, H-4', H-5', H-6', H-7'), 1.44 (p, $\left.J=7.6 \mathrm{~Hz}, 2 \mathrm{H}, \mathrm{H}-3^{\prime}\right), 1.87$ (p, $\left.J=7.2 \mathrm{~Hz}, 2 \mathrm{H}, \mathrm{H}-2^{\prime}\right), 3.98$ (t, $J=6.7 \mathrm{~Hz}, 2 \mathrm{H}$, H-1'), 6.12 (s, 1H, H-3), 7.68 (dt, $J=1.5,7.5 \mathrm{~Hz}, 1 \mathrm{H}, \mathrm{H}-7), 7.71$ (dt, $J=1.0,7.5 \mathrm{~Hz}, 1 \mathrm{H}, \mathrm{H}-6), 8.05$ $(\mathrm{dd}, J=1.0,7.0 \mathrm{~Hz}, 1 \mathrm{H}, \mathrm{H}-8), 8.10(\mathrm{dd}, J=1.5,7.5 \mathrm{~Hz}, 1 \mathrm{H}, \mathrm{H}-5) ;{ }^{13} \mathrm{C}-\mathrm{NMR}\left(125 \mathrm{MHz}, \mathrm{CDCl}_{3}\right) \delta \mathrm{c} 14.08$ $\left(\mathrm{CH}_{3}\right), 22.63\left({\left.\mathrm{C}-7^{\prime}\right),}^{\prime} 25.85\left(\mathrm{C}-2^{\prime}\right), 28.26\left(\mathrm{C}-3^{\prime}\right), 29.14\left(\mathrm{C}-4^{\prime}\right), 29.20\left(\mathrm{C}-5^{\prime}\right), 31.75\left(\mathrm{C}-6^{\prime}\right), 69.69\left(\mathrm{C}-1^{\prime}\right)\right.$, 110.19 (C-3), 126.11 (C-8), 126.67 (C-5), 131.20 (C-9), 132.05 (C-10), 133.24 (C-6), 134.20 (C-7), $159.92(\mathrm{C}-2), 180.18(\mathrm{C}=\mathrm{O}), 185.09(\mathrm{C}=\mathrm{O})$; LC-MS $\left(\mathrm{ESI}^{+}, \mathrm{m} / z\right)$ calculated for $\mathrm{C}_{18} \mathrm{H}_{22} \mathrm{O}_{3}$ : 286.16, found for $309.25[\mathrm{M}+\mathrm{Na}]^{+}$; HRMS-ESI: $m / z$ calculated for $\mathrm{C}_{18} \mathrm{H}_{22} \mathrm{O}_{3}$ : $286.1569[\mathrm{M}]^{+}$, found for 286.1564 .

2-Hydroxy-3-dodectyl-1,4-naphthoquinone (8a). The reaction produced $\mathbf{8 a}$ in $56.3 \%$ as a yellow solid; mp 88.4-88.9 ${ }^{\circ} \mathrm{C}$ (lit. [35] 85-87 ${ }^{\circ} \mathrm{C}$ ). ${ }^{1} \mathrm{H}-\mathrm{NMR}\left(500 \mathrm{MHz}, \mathrm{CDCl}_{3}\right) \delta_{\mathrm{H}} 0.86\left(\mathrm{t}, J=7.0 \mathrm{~Hz}, 3 \mathrm{H}, \mathrm{CH}_{3}\right)$, 1.23-1.35 (m, 18H, H-3', H-4', H-5', H-6', H-7', H-8', H-9', H-10', H-11'), 1.51 (p, J= 7.5 Hz, 2H, H-2'), 
$2.58\left(\mathrm{t}, J=7.7 \mathrm{~Hz}, 2 \mathrm{H}, \mathrm{H}-1^{\prime}\right), 7.26(\mathrm{~s}, 1 \mathrm{H}, 2-\mathrm{OH}), 7.61$ (dt, $\left.J=0.8,7.5 \mathrm{~Hz}, 1 \mathrm{H}, \mathrm{H}-7\right), 7.73$ (dt, $J=0.8$, $7.5 \mathrm{~Hz}, 1 \mathrm{H}, \mathrm{H}-6), 8.00$ (d, $J=7.5 \mathrm{~Hz}, 1 \mathrm{H}, \mathrm{H}-8), 8.05$ (d, $J=7.5 \mathrm{~Hz}, 1 \mathrm{H}, \mathrm{H}-5) ;{ }^{13} \mathrm{C}-\mathrm{NMR}(125 \mathrm{MHz}$, $\left.\mathrm{CDCl}_{3}\right) \delta_{\mathrm{C}} 14.33\left(\mathrm{CH}_{3}\right), 22.91\left(\mathrm{C}-1^{\prime}\right), 23.62\left(\mathrm{C}-11^{\prime}\right), 28.53\left(\mathrm{C}-2^{\prime}\right), 29.57\left(\mathrm{C}-3^{\prime}\right), 29.68\left(\mathrm{C}-4^{\prime}\right), 29.80\left(\mathrm{C}-5^{\prime}\right)$, $29.86\left(\mathrm{C}^{6} 6^{\prime}\right), 29.88$ (C-7'), 29.92 (C-8'), 30.02 (C-9'), 32.14 (C-10'), 125.09 (C-3), 126.26 (C-8), 127.00 (C-5), 129.69 (C-9), 133.05 (C-6), 133.21 (C-10), 135.04 (C-7), 153.20 (C-2), $181.71(\mathrm{C}=\mathrm{O})$, $184.93(\mathrm{C}=\mathrm{O})$; LC-MS $\left(\mathrm{ESI}^{-}, \mathrm{m} / z\right)$ calculated for $\mathrm{C}_{22} \mathrm{H}_{30} \mathrm{O}_{3}: 342.22$, found for $341.38[\mathrm{M}-\mathrm{H}]^{-}$; HRMS-ESI: $m / z$ calculated for $\mathrm{C}_{22} \mathrm{H}_{30} \mathrm{O}_{3}: 342.2195[\mathrm{M}]^{+}$, found for 342.2189.

2-Dodectyloxy-1,4-naphthoquinone $(\mathbf{8 b})$. The reaction produced $\mathbf{8 b}$ in $6.9 \%$ as a yellow solid; $\mathrm{mp}$ 96.1-96.7 ${ }^{\circ} \mathrm{C} .{ }^{1} \mathrm{H}-\mathrm{NMR}\left(500 \mathrm{MHz}, \mathrm{CDCl}_{3}\right) \delta_{\mathrm{H}} 0.86\left(\mathrm{t}, J=7.0 \mathrm{~Hz}, 3 \mathrm{H}, \mathrm{CH}_{3}\right), 1.24-1.33$ (m, 16H, H-4', H-5', H-6', H-7', H-8', H-9', H-10', H-11'), 1.44 (p, J=7.5 Hz, 2H, H-3'), 1.87 (p, J=7.1 Hz, 2H, H-2'), $3.98\left(\mathrm{t}, J=6.7 \mathrm{~Hz}, 2 \mathrm{H}, \mathrm{H}-1^{\prime}\right), 6.13(\mathrm{~s}, 1 \mathrm{H}, \mathrm{H}-3), 7.68$ (t, $\left.J=7.3 \mathrm{~Hz}, 1 \mathrm{H}, \mathrm{H}-7\right), 7.72$ (t, $J=7.3 \mathrm{~Hz}, 1 \mathrm{H}$, H-6), 8.05 (d, $J=7.4 \mathrm{~Hz}, 1 \mathrm{H}, \mathrm{H}-8), 8.10(\mathrm{~d}, J=7.5 \mathrm{~Hz}, 1 \mathrm{H}, \mathrm{H}-5) ;{ }^{13} \mathrm{C}-\mathrm{NMR}\left(125 \mathrm{MHz}, \mathrm{CDCl}_{3}\right) \delta \mathrm{C}$

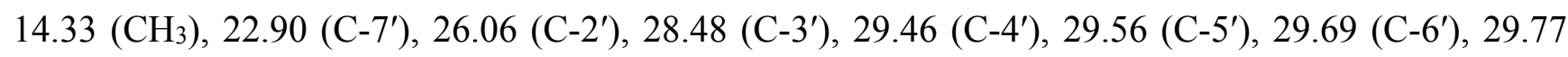
(C-7'), 29.83 (C-8'), 29.84 (C-9'), 32.13 (C-10'), 69.90 (C-1'), 110.40 (C-3), 126.32 (C-8), 126.89 (C-5), 131.42 (C-9), 132.26 (C-10), 133.46 (C-6), 134.42 (C-7), 160.13 (C-2), 180.40 (C=O), 185.31 $(\mathrm{C}=\mathrm{O})$; LC-MS $\left(\mathrm{ESI}^{-}, \mathrm{m} / z\right)$ calculated for $\mathrm{C}_{22} \mathrm{H}_{30} \mathrm{O}_{3}: 342.22$, found for 341.30 [M - H] $]^{-}$; HRMS-ESI: $\mathrm{m} / z$ calculated for $\mathrm{C}_{22} \mathrm{H}_{30} \mathrm{O}_{3}: 342.2195[\mathrm{M}]^{+}$, found for 342.2197 .

2-Hydroxy-3-isoprenyl-1,4-naphthoquinone (9a). The reaction produced 9a in 58.2\% as a yellow solid; mp 142.5-144.0 ${ }^{\circ} \mathrm{C}$ (lit. [36] 141-143 ${ }^{\circ} \mathrm{C}$ ). ${ }^{1} \mathrm{H}-\mathrm{NMR}\left(500 \mathrm{MHz}, \mathrm{CDCl}_{3}\right) \delta_{\mathrm{H}} 1.66$ (s, 3H, CH3), 1.77 (s, $\left.3 \mathrm{H}, \mathrm{CH}_{3}\right), 3.29\left(\mathrm{~d}, J=7.4 \mathrm{~Hz}, 2 \mathrm{H}, \mathrm{H}-1^{\prime}\right), 5.17-5.21$ (m, 2H, H-2'), 7.27 (s, 1H, 2-OH), 7.66 (dt, $J=1.1,7.4 \mathrm{~Hz}, 1 \mathrm{H}, \mathrm{H}-7), 7.73$ (dt, $J=1.4,7.6 \mathrm{~Hz}, 1 \mathrm{H}, \mathrm{H}-6), 8.05$ (dd, $J=1.0,7.4 \mathrm{~Hz}, 1 \mathrm{H}, \mathrm{H}-8), 8.10$ $(\mathrm{dd}, J=1.0,7.7 \mathrm{~Hz}, 1 \mathrm{H}, \mathrm{H}-5) ;{ }^{13} \mathrm{C}-\mathrm{NMR}\left(125 \mathrm{MHz}, \mathrm{CDCl}_{3}\right) \delta \mathrm{C} 18.12\left(\mathrm{CH}_{3}\right), 22.84\left(\mathrm{CH}_{3}\right), 25.98$ (C-1'), 119.85 (C-3), 123.68 (C-2'), 126.28 (C-8), 127.01 (C-5), 129.65 (C-9), 133.09 (C-6), 133.14 (C-10), 134.09 (C-3'), 135.08 (C-7), 152.87 (C-2), 181.93 (C=O), 184.79 (C=O); LC-MS (ESI $\left.{ }^{-}, m / z\right)$ calculated for $\mathrm{C}_{15} \mathrm{H}_{14} \mathrm{O}_{3}: 242.09$, found for 241.16 [M - H] $]^{-}$; HRMS-ESI: $m / z$ calculated for $\mathrm{C}_{15} \mathrm{H}_{14} \mathrm{O}_{3}$ : $242.0943[\mathrm{M}]^{+}$, found for 242.0948 .

2-Isoprenyloxy-1,4-naphthoquinone (9b). The reaction produced $\mathbf{9 b}$ in $4.8 \%$ as a yellow solid; $\mathrm{mp}$ 158.0-159.6 ${ }^{\circ} \mathrm{C}$ (lit. [37] 150-151 ${ }^{\circ} \mathrm{C}$ ). ${ }^{1} \mathrm{H}-\mathrm{NMR}\left(500 \mathrm{MHz}, \mathrm{CDCl}_{3}\right) \delta_{\mathrm{H}} 1.74\left(\mathrm{~s}, 3 \mathrm{H}, \mathrm{CH}_{3}\right), 1.79(\mathrm{~s}, 3 \mathrm{H}$, $\left.\mathrm{CH}_{3}\right), 4.57$ (d, $\left.J=7.8 \mathrm{~Hz}, 2 \mathrm{H}, \mathrm{H}-1^{\prime}\right), 5.46-5.49$ (m, 2H, H-2'), 6.14 (s, 1H, H-3), 7.68 (dt, J = 1.5, $7.5 \mathrm{~Hz}$, $1 \mathrm{H}, \mathrm{H}-7), 7.72$ (dt, $J=1.5,7.5 \mathrm{~Hz}, 1 \mathrm{H}, \mathrm{H}-6), 8.06$ (dd, $J=1.5,7.5 \mathrm{~Hz}, 1 \mathrm{H}, \mathrm{H}-8), 8.10$ (dd, $J=1.5$, $7.5 \mathrm{~Hz}, 1 \mathrm{H}, \mathrm{H}-5) ;{ }^{13} \mathrm{C}-\mathrm{NMR}\left(125 \mathrm{MHz}, \mathrm{CDCl}_{3}\right) \delta \mathrm{C} 18.58\left(\mathrm{CH}_{3}\right), 26.05\left(\mathrm{CH}_{3}\right), 66.63\left(\mathrm{C}-1^{\prime}\right), 110.73(\mathrm{C}-3)$, 117.41 (C-2'), 126.33 (C-8), 126.92 (C-5), 131.41 (C-9), 132.26 (C-10), 133.46 (C-6), 134.43 (C-7), $140.73\left(\mathrm{C}-3^{\prime}\right), 159.80(\mathrm{C}-2), 180.51(\mathrm{C}=\mathrm{O}), 185.28(\mathrm{C}=\mathrm{O})$; LC-MS $\left(\mathrm{ESI}^{-}, m / z\right)$ calculated for $\mathrm{C}_{15} \mathrm{H}_{14} \mathrm{O}_{3}$ : 242.09, found for $241.23[\mathrm{M}-\mathrm{H}]^{-}$; HRMS-ESI: $m / z$ calculated for $\mathrm{C}_{15} \mathrm{H}_{14} \mathrm{O}_{3}: 242.0943$ [M] $]^{+}$, found for 242.0941 .

2-Hydroxy-3-geranyl-1,4-naphthoquinone (10a). The reaction produced 10a in 50.8\% as a yellow solid; mp 112.0-112.5 ${ }^{\circ} \mathrm{C}$ [38]. ${ }^{1} \mathrm{H}-\mathrm{NMR}\left(500 \mathrm{MHz}, \mathrm{CDCl}_{3}\right) \delta_{\mathrm{H}} 1.59$ (s, 3H, $\left.\mathrm{CH}_{3}\right), 1.65$ (s, 3H, $\mathrm{CH}_{3}$ ), $1.81\left(\mathrm{~s}, 3 \mathrm{H}, \mathrm{CH}_{3}\right), 1.98-2.01$ (m, 2H, H-5'), 2.06-2.09 (m, 2H, H-6'), 3.34 (d, J = 7.5 Hz, 2H, H-1'), 5.06-5.09 (m, 1H, H-7'), 5.23 (dt, $\left.J=1.0,7.5 \mathrm{~Hz}, 1 \mathrm{H}, \mathrm{H}-2^{\prime}\right), 7.31$ (s, 1H, 2-OH), 7.70 (dt, $J=1.0,7.5 \mathrm{~Hz}$, 
1H, H-7), 7.78 (dt, $J=1.0,7.5 \mathrm{~Hz}, 1 \mathrm{H}, \mathrm{H}-6), 8.10$ (dd, $J=1.5,7.5 \mathrm{~Hz}, 1 \mathrm{H}, \mathrm{H}-8), 8.15$ (dd, $J=1.0,7.5 \mathrm{~Hz}$, 1H, H-5); ${ }^{13} \mathrm{C}-\mathrm{NMR}\left(125 \mathrm{MHz}, \mathrm{CDCl}_{3}\right) \delta_{\mathrm{C}} 16.47\left(\mathrm{CH}_{3}\right), 17.88\left(\mathrm{CH}_{3}\right), 22.77\left(\mathrm{CH}_{3}\right), 25.87\left(\mathrm{C}-1^{\prime}\right), 26.82$ (C-6'), 39.96 (C-5'), 119.67 (C-3), 123.76 (C-2'), 124.41 (C-7'), 126.28 (C-8), 127.00 (C-5), 129.65 (C-8'), 131.61 (C-9), 133.08 (C-6), 133.15 (C-10), 135.08 (C-7), 137.61 (C-3'), 152.88 (C-2), 181.94 $(\mathrm{C}=\mathrm{O}), 184.74(\mathrm{C}=\mathrm{O})$; LC-MS $\left(\mathrm{ESI}^{-}, \mathrm{m} / z\right)$ calculated for $\mathrm{C}_{20} \mathrm{H}_{22} \mathrm{O}_{3}: 310.16$, found for $309.12[\mathrm{M}-\mathrm{H}]^{-}$; HRMS-ESI: $m / z$ calculated for $\mathrm{C}_{20} \mathrm{H}_{22} \mathrm{O}_{3}: 310.1569[\mathrm{M}]^{+}$, found for 310.1572 .

2-Geranyloxy-1,4-naphthoquinone (10b). The reaction produced $\mathbf{1 0 b}$ in $5.2 \%$ as a pale yellow liquid. ${ }^{1} \mathrm{H}-\mathrm{NMR}\left(500 \mathrm{MHz}, \mathrm{CDCl}_{3}\right) \delta_{\mathrm{H}} 1.59\left(\mathrm{~s}, 3 \mathrm{H}, \mathrm{CH}_{3}\right), 1.65\left(\mathrm{~s}, 3 \mathrm{H}, \mathrm{CH}_{3}\right), 1.81\left(\mathrm{~s}, 3 \mathrm{H}, \mathrm{CH}_{3}\right), 1.99-2.02(\mathrm{~m}$, 2H, H-5'), 2.07-2.10 (m, 2H, H-6'), 4.58 (d, J=6.6 Hz, 2H, H-1'), 5.06-5.10 (m, 1H, H-7'), 5.46 (dt, $\left.J=0.8,6.6 \mathrm{~Hz}, 1 \mathrm{H}, \mathrm{H}-2^{\prime}\right), 6.14(\mathrm{~s}, 1 \mathrm{H}, \mathrm{H}-3), 7.68$ (dt, $\left.J=1.0,7.5 \mathrm{~Hz}, 1 \mathrm{H}, \mathrm{H}-7\right), 7.74$ (dt, $J=1.0$, $7.5 \mathrm{~Hz}, 1 \mathrm{H}, \mathrm{H}-6), 8.06$ (dd, $J=1.5,7.5 \mathrm{~Hz}, 1 \mathrm{H}, \mathrm{H}-8), 8.10$ (dt, $J=1.0,7.5 \mathrm{~Hz}, 1 \mathrm{H}, \mathrm{H}-5)$; ${ }^{13} \mathrm{C}-\mathrm{NMR}$ $\left(125 \mathrm{MHz}, \mathrm{CDCl}_{3}\right) \delta_{\mathrm{C}} 16.47\left(\mathrm{CH}_{3}\right), 17.68\left(\mathrm{CH}_{3}\right), 25.70\left(\mathrm{CH}_{3}\right), 26.71\left(\mathrm{C}-6^{\prime}\right), 39.65\left(\mathrm{C}-5^{\prime}\right), 66.51\left(\mathrm{C}-1^{\prime}\right)$, 110.56 (C-3), 117.22 (C-2'), 124.37 (C-7'), 126.23 (C-8), 126.88 (C-5), 131.18 (C-8'), 132.06 (C-9), 133.18 (C-6), 134.26 (C-10), 135.73 (C-7), 141.56 (C-3'), 159.56 (C-2), 180.29 (C=O), 185.06 (C=O); LC-MS $\left(\mathrm{ESI}^{-}, \mathrm{m} / z\right)$ calculated for $\mathrm{C}_{20} \mathrm{H}_{22} \mathrm{O}_{3}: 310.16$, found for $309.06[\mathrm{M}-\mathrm{H}]^{-}$; HRMS-ESI: $m / z$ calculated for $\mathrm{C}_{20} \mathrm{H}_{22} \mathrm{O}_{3}: 310.1569[\mathrm{M}]^{+}$, found for 310.1574 .

2-Hydroxy-3-farnesyl-1,4-naphthoquinone (11a). The reaction produced 11a in $35.2 \%$ as a yellow solid; mp 84.4-84.9 ${ }^{\circ} \mathrm{C}$ (lit. [39] 68-69 ${ }^{\circ} \mathrm{C}$ ). ${ }^{1} \mathrm{H}-\mathrm{NMR}\left(500 \mathrm{MHz}, \mathrm{CDCl}_{3}\right) \delta_{\mathrm{H}} 1.54$ (s, 3H, CH3), 1.54 (s, $\left.6 \mathrm{H}, \mathrm{CH}_{3}\right), 1.77$ (s, 3H, CH3), 1.92-1.95 (m, 2H, H-5'), 1.97-2.00 (m, 4H, H-9', H-10') 2.02-2.07 (m, 2H, H-6'), 3.30 (d, $\left.J=7.5 \mathrm{~Hz}, 2 \mathrm{H}, \mathrm{H}-1^{\prime}\right), 5.00-5.05$ (m, 2H, H-7', H-12') 5.20 (t, 1H, $J=7.3 \mathrm{~Hz}, 1 \mathrm{H}, \mathrm{H}-2^{\prime}$ ), 7.28 (s, 1H, 2-OH), 7.65 (t, $J=7.5 \mathrm{~Hz}, 1 \mathrm{H}, \mathrm{H}-7), 7.73$ (t, $J=7.5 \mathrm{~Hz}, 1 \mathrm{H}, \mathrm{H}-6), 8.05$ (d, $J=7.5 \mathrm{~Hz}, 1 \mathrm{H}$, $\mathrm{H}-8), 8.11(\mathrm{~d}, J=7.5 \mathrm{~Hz}, 1 \mathrm{H}, \mathrm{H}-5) ;{ }^{13} \mathrm{C}-\mathrm{NMR}\left(125 \mathrm{MHz}, \mathrm{CDCl}_{3}\right) \delta_{\mathrm{c}} 16.22\left(\mathrm{CH}_{3}\right), 16.48\left(\mathrm{CH}_{3}\right), 17.86$ $\left(\mathrm{CH}_{3}\right), 22.77\left(\mathrm{C}-1^{\prime}\right), 25.90\left(\mathrm{CH}_{3}\right), 26.69\left(\mathrm{C}-6^{\prime}\right), 26.94\left(\mathrm{C}-11^{\prime}\right), 39.89\left(\mathrm{C}-5^{\prime}\right), 39.95\left(\mathrm{C}-9^{\prime}\right), 119.69(\mathrm{C}-3)$, $123.75\left(\mathrm{C}-2^{\prime}\right), 124.24\left(\mathrm{C}-7^{\prime}\right), 124.57$ (C-11'), 126.27 (C-8), 127.00 (C-5), 129.66 (C-9), 131.43 (C-10), 133.06 (C-6), 133.14 (C-12'), 135.06 (C-7), 135.24 (C-8'), $137.60\left(\mathrm{C}-3^{\prime}\right), 152.89(\mathrm{C}-2), 181.92(\mathrm{C}=\mathrm{O})$, $184.74(\mathrm{C}=\mathrm{O})$; LC-MS $\left(\mathrm{ESI}^{-}, \mathrm{m} / z\right)$ calculated for $\mathrm{C}_{25} \mathrm{H}_{30} \mathrm{O}_{3}$ : 378.22, found for $377.23[\mathrm{M}-\mathrm{H}]^{-}$; HRMS-ESI: $m / z$ calculated for $\mathrm{C}_{25} \mathrm{H}_{30} \mathrm{O}_{3}: 378.2195[\mathrm{M}]^{+}$, found for 378.2193.

2-Farnesyloxy-1,4-naphthoquinone (11b). The reaction produced $\mathbf{1 1 b}$ in $7.4 \%$ as a yellow liquid. ${ }^{1} \mathrm{H}-\mathrm{NMR}\left(500 \mathrm{MHz}, \mathrm{CDCl}_{3}\right) \delta_{\mathrm{H}} 1.56\left(\mathrm{~s}, 3 \mathrm{H}, \mathrm{CH}_{3}\right), 1.58\left(\mathrm{~s}, 6 \mathrm{H}, \mathrm{CH}_{3}\right), 1.74\left(\mathrm{~s}, 3 \mathrm{H}, \mathrm{CH}_{3}\right), 1.92-1.95$ (m, 2H, H-5'), 2.00-2.03 (m, 2H, H-6') 2.08-2.12 (m, 4H, H-9', H-10'), 4.60 (d, J=6.6 Hz, 2H, H-1'), 5.04-5.08 (m, 2H, H-7', H-12') 5.47 (dt, 1H, $J=0.8,6.6$ Hz, 1H, H-2'), 6.14 (s, 1H, H-3), 7.69 (dt, $J=1.5,7.5 \mathrm{~Hz}, 1 \mathrm{H}, \mathrm{H}-7), 7.72$ (dt, $J=1.5,7.5 \mathrm{~Hz}, 1 \mathrm{H}, \mathrm{H}-6), 8.06$ (dd, $J=1.5,7.5 \mathrm{~Hz}, 1 \mathrm{H}, \mathrm{H}-8), 8.10$ (dd, $J=1.5,7.5 \mathrm{~Hz}, 1 \mathrm{H}, \mathrm{H}-5) ;{ }^{13} \mathrm{C}-\mathrm{NMR}\left(125 \mathrm{MHz}, \mathrm{CDCl}_{3}\right) \delta \mathrm{C} 16.05\left(\mathrm{CH}_{3}\right), 16.88\left(\mathrm{CH}_{3}\right), 17.68\left(\mathrm{CH}_{3}\right)$, $25.70\left(\mathrm{CH}_{3}\right), 26.09\left(\mathrm{C}-6^{\prime}\right), 26.71\left(\mathrm{C}-11^{\prime}\right), 39.53\left(\mathrm{C}-5^{\prime}\right), 39.67\left(\mathrm{C}-9^{\prime}\right), 66.50\left(\mathrm{C}-1^{\prime}\right), 110.55(\mathrm{C}-3), 116.91$ (C-2'), 123.39 (C-7'), 124.28 (C-11'), 126.12 (C-8), 126.70 (C-5), 131.20 (C-9), 131.33 (C-10), 132.04 (C-12'), 133.24 (C-6), 134.21 (C-7), 135.72 (C-8'), 143.63 (C-3'), 159.58 (C-2), 180.31 (C=O), 185.04 $(\mathrm{C}=\mathrm{O})$; LC-MS $\left(\mathrm{ESI}^{-}, \mathrm{m} / z\right)$ calculated for $\mathrm{C}_{25} \mathrm{H}_{30} \mathrm{O}_{3}$ : 378.22 , found for $377.26[\mathrm{M}-\mathrm{H}]^{-}$; HRMS-ESI: $m / z$ calculated for $\mathrm{C}_{25} \mathrm{H}_{30} \mathrm{O}_{3}: 378.2195[\mathrm{M}]^{+}$, found for 378.2190 . 


\subsection{5-Hydroxy-1,4-Naphthoquinone (Juglone, 3)}

A suspension of 1,5-dihydroxynaphthene $(1 \mathrm{~g}, 6.25 \mathrm{mmol})$ in $\mathrm{THF} / \mathrm{H}_{2} \mathrm{O}(50 \mathrm{~mL}, 1 / 1, v / v)$ was placed in a $100 \mathrm{~mL}$, three-necked flask fitted with a mechanical stirrer and a gas inlet tube and a strong current of air was bubbled through it. Then, periodic acid (3.12 g, $13.7 \mathrm{mmol})$ was added with vigorous stirring at room temperature in the dark over $1 \mathrm{~h}$, and the resultant mixture was stirred for $4 \mathrm{~h}$. The mixture was filtered, washed with acetonitrile, and the solvent removed under reduced pressure. The crude product was purified using silica gel with ethyl acetate/ $n$-hexane (1:5) as the solvent to afford 5-hydroxy-1,4-naphthoquinone (juglone, 3) (735 mg, $4.22 \mathrm{mmol}, 67.6 \%)$ as a brown-red solid; $\mathrm{mp}$ 146.0-148.2 ${ }^{\circ} \mathrm{C}$ (lit. [40] $152{ }^{\circ} \mathrm{C}$ ). ${ }^{1} \mathrm{H}-\mathrm{NMR}\left(500 \mathrm{MHz}, \mathrm{CDCl}_{3}\right) \delta_{\mathrm{H}} 6.93$ (s, 2H, H-2, H-3), 7.26 (dd, $J=1.5,7.5 \mathrm{~Hz}, 1 \mathrm{H}, \mathrm{H}-6), 7.59-7.63$ (m, 2H, H-7, H-8), 11.88 (s, 1H, 5-OH); ${ }^{13} \mathrm{C}-\mathrm{NMR}(125 \mathrm{MHz}$, $\left.\mathrm{CDCl}_{3}\right) \delta_{\mathrm{C}} 114.97$ (C-10), 119.15 (C-6), 124.49 (C-8), 131.76 (C-9), 136.56 (C-7), 138.65 (C-3), 139.59 (C-2), $161.45(\mathrm{C}-5), 184.25(\mathrm{C}=\mathrm{O}), 190.28(\mathrm{C}=\mathrm{O})$; LC-MS (ESI $\left.{ }^{-}, m / z\right)$ calculated for $\mathrm{C}_{10} \mathrm{H}_{6} \mathrm{O}_{3}$ : 174.03, found for $173.10[\mathrm{M}-\mathrm{H}]^{-}$; HRMS-ESI: $m / z$ calculated for $\mathrm{C}_{10} \mathrm{H}_{6} \mathrm{O}_{3}: 174.0317[\mathrm{M}]^{+}$, found for 174.0313 .

\subsection{General Proceed Amination of Juglone with Alkyl Amine}

A suspension of juglone $(200 \mathrm{mg}, 1.15 \mathrm{mmol})$ and alkyl amine $(1.15 \mathrm{mmole})$ in $50 \mathrm{~mL}$ of ethanol was stirred for $1 \mathrm{~h}$ under reflux. The mixture was poured into water, $2 \mathrm{~mL}$ of $1 \mathrm{~N}$ hydrochloric acid was added, the precipitate was filtered off, washed with water, dried, and dissolved in chloroform, and the solution was applied to a column charged with silica gel. The column was eluted with ethyl acetate $/ n$-hexane (1/5) to give the 2 -amination and 3 -amination products, respectively.

2-Butylamino-5-hydroxy-1,4-naphthoquinone (13a). The reaction produced 13a in $13.9 \%$ as an orange red solid; mp 154.6-155.4 ${ }^{\circ} \mathrm{C}$ (lit. [41] 156-157 $\left.{ }^{\circ} \mathrm{C}\right) .{ }^{1} \mathrm{H}-\mathrm{NMR}\left(500 \mathrm{MHz}, \mathrm{CDCl}_{3}\right) \delta_{\mathrm{H}} 0.96(\mathrm{t}, J=7.4 \mathrm{~Hz}$, $3 \mathrm{H}, \mathrm{CH}_{3}$ ), 1.43 (p, $\left.J=7.5 \mathrm{~Hz}, 2 \mathrm{H}, \mathrm{H}-2^{\prime}\right), 1.67$ (p, $\left.J=7.5 \mathrm{~Hz}, 2 \mathrm{H}, \mathrm{H}-3^{\prime}\right), 3.17$ (q, $J=6.9 \mathrm{~Hz}, 2 \mathrm{H}, \mathrm{H}-1^{\prime}$ ), 5.61 (s, 1H, H-3), 6.04 (s, 1H, -NH), 7.22 (dd, $J=0.8,8.3 \mathrm{~Hz}, 1 \mathrm{H}, \mathrm{H}-8), 7.44$ (t, $J=8.0 \mathrm{~Hz}, 1 \mathrm{H}, \mathrm{H}-7)$, $7.56(\mathrm{dd}, 1 \mathrm{H}, J=0.8,7.6 \mathrm{~Hz}, \mathrm{H}-6), 13.08$ (s, $1 \mathrm{H}, 5-\mathrm{OH}) ;{ }^{13} \mathrm{C}-\mathrm{NMR}\left(125 \mathrm{MHz}, \mathrm{CDCl}_{3}\right) \delta_{\mathrm{C}} 13.90\left(\mathrm{CH}_{3}\right)$, 20.40 (C-2'), 30.43 (C-3'), 42.63 (C-1'), 99.81 (C-3), 115.19 (C-9), 119.25 (C-6), 126.18 (C-8), 130.70 (C-10), 134.05 (C-7), 148.90 (C-2), 161.33 (C-5), $181.41(\mathrm{C}=\mathrm{O}), 189.14(\mathrm{C}=\mathrm{O})$; LC-MS (ESI $\left.{ }^{+}, m / z\right)$ calculated for $\mathrm{C}_{14} \mathrm{H}_{15} \mathrm{NO}_{3}$ : 245.11, found for $268.24[\mathrm{M}+\mathrm{Na}]^{+}$; HRMS-ESI: $m / z$ calculated for $\mathrm{C}_{14} \mathrm{H}_{16} \mathrm{O}_{3} \mathrm{~N}: 246.1125[\mathrm{M}+\mathrm{H}]^{+}$, found for 246.1120 .

3-Butylamino-5-hydroxy-1,4-naphthoquinone (13b). The reaction produced $\mathbf{1 3 b}$ in $6.9 \%$ as an orange red solid; mp 125.3-126.5 ${ }^{\circ} \mathrm{C}$ (lit. [41] 111-112 ${ }^{\circ} \mathrm{C}$ ). ${ }^{1} \mathrm{H}-\mathrm{NMR}\left(500 \mathrm{MHz}, \mathrm{CDCl}_{3}\right) \delta_{\mathrm{H}} 0.96(\mathrm{t}, J=7.5 \mathrm{~Hz}$, $\left.3 \mathrm{H}, \mathrm{CH}_{3}\right), 1.42$ (h, $\left.J=7.5 \mathrm{~Hz}, 2 \mathrm{H}, \mathrm{H}-3^{\prime}\right), 1.67$ (p, $\left.J=7.5 \mathrm{~Hz}, 2 \mathrm{H}, \mathrm{H}-2^{\prime}\right), 3.17$ (q, $J=6.9 \mathrm{~Hz}, 2 \mathrm{H}, \mathrm{H}-1^{\prime}$ ), 5.70 (s, 1H, H-3), 5.85 (bs, 1H, -NH), 7.12 (dd, J=2.3, 7.0 Hz, 1H, H-8), 7.57-7.62 (m, 2H, H-6, H-7), 11.52 (s, 1H, 5-OH); ${ }^{13} \mathrm{C}-\mathrm{NMR}\left(125 \mathrm{MHz}, \mathrm{CDCl}_{3}\right) \delta_{\mathrm{C}} 13.91\left(\mathrm{CH}_{3}\right), 20.42\left(\mathrm{C}-2^{\prime}\right), 30.45\left(\mathrm{C}-3^{\prime}\right), 42.56$ (C-1'), 101.50 (C-3), 114.31 (C-9), 118.95 (C-6), 122.37 (C-8), 133.82 (C-10), 137.91 (C-7), 147.97 (C-2), $161.89(\mathrm{C}-5), 182.42(\mathrm{C}=\mathrm{O}), 186.36(\mathrm{C}=\mathrm{O})$; LC-MS $\left(\mathrm{ESI}^{+}, \mathrm{m} / z\right)$ calculated for $\mathrm{C}_{14} \mathrm{H}_{15} \mathrm{NO}_{3}$ : 245.11, found for $268.29[\mathrm{M}+\mathrm{Na}]^{+}$; HRMS-ESI: $m / z$ calculated for $\mathrm{C}_{14} \mathrm{H}_{16} \mathrm{O}{ }_{3} \mathrm{~N}: 246.1125[\mathrm{M}+\mathrm{H}]^{+}$, found for 246.1121 . 
2-Hexylamino-5-hydroxy-1,4-naphthoquinone (14a). The reaction produced 14a in $15.1 \%$ as an orange red solid; mp 126.0-127.5 ${ }^{\circ} \mathrm{C} .{ }^{1} \mathrm{H}-\mathrm{NMR}\left(500 \mathrm{MHz}, \mathrm{CDCl}_{3}\right) \delta_{\mathrm{H}} 0.88$ (t, $\left.J=7.5 \mathrm{~Hz}, 3 \mathrm{H}, \mathrm{CH}_{3}\right), 1.30-1.32$ (m, 4H, H-4', H-5'), 1.36-1.40 (m, 2H, H-3'), 1.67 (p, $\left.J=7.3 \mathrm{~Hz}, 2 \mathrm{H}, \mathrm{H}-2^{\prime}\right), 3.16$ (q, $J=6.8 \mathrm{~Hz}, 2 \mathrm{H}, \mathrm{H}-1^{\prime}$ ), 5.60 (s, 1H, H-3), 6.05 (bs, 1H, -NH), 7.22 (d, $J=8.4$ Hz, 1H, H-8), 7.44 (t, $J=7.9$ Hz, 1H, H-7), 7.56 (d, $J=7.2 \mathrm{~Hz}, 1 \mathrm{H}, \mathrm{H}-6), 13.08$ (s, 1H, 5-OH); ${ }^{13} \mathrm{C}-\mathrm{NMR}$ (125 MHz, CDCl 3$) \delta_{\mathrm{c}} 14.19\left(\mathrm{CH}_{3}\right), 22.72\left(\mathrm{C}-5^{\prime}\right)$, 26.88 (C-2'), 28.38 (C-3'), 31.59 (C-4'), 42.93 (C-1'), 99.78 (C-3), 115.18 (C-9), 119.24 (C-6), 126.16 (C-8), 130.68 (C-10), 134.03 (C-7), 148.87 (C-2), 161.31 (C-5), 181.40 (C=O), 189.12 (C=O); LC-MS $\left(\mathrm{ESI}^{+}, m / z\right)$ calculated for $\mathrm{C}_{16} \mathrm{H}_{19} \mathrm{NO}_{3}: 273.14$, found for $296.29[\mathrm{M}+\mathrm{Na}]^{+}$; HRMS-ESI: $m / z$ calculated for $\mathrm{C}_{16} \mathrm{H}_{20} \mathrm{O} 3 \mathrm{~N}$ : $274.1438[\mathrm{M}+\mathrm{H}]^{+}$, found for 274.1435

3-Hexylaminp-5-hydroxy-1,4-naphthoquinone (14b). The reaction produced $\mathbf{1 4 b}$ in $24.1 \%$ as an orange red solid; mp $110.2-111.1^{\circ} \mathrm{C} .{ }^{1} \mathrm{H}-\mathrm{NMR}\left(500 \mathrm{MHz}, \mathrm{CDCl}_{3}\right) \delta_{\mathrm{H}} 0.88\left(\mathrm{t}, J=6.4 \mathrm{~Hz}, 3 \mathrm{H}, \mathrm{CH}_{3}\right), 1.31-1.32$ (m, 4H, H-4', H-5'), 1.39 (p, J=6.9 Hz, 2H, H-3') 1.69 (p, J=7.3 Hz, 2H, H-2'), 3.16 (q, J=6.6 Hz, 2H, H-1'), 5.69 (s, 1H, H-2), 5.87 (bs, 1H, -NH), 7.11 (dd, J=2.0, 7.2 Hz, 1H, H-6), 7.57-7.61 (m, 2H, H-7, H-8), 11.52 (s, 1H, 5-OH); ${ }^{13} \mathrm{C}-\mathrm{NMR}\left(125 \mathrm{MHz}, \mathrm{CDCl}_{3}\right) \delta \mathrm{c} 13.97\left(\mathrm{CH}_{3}\right), 22.50\left(\mathrm{C}-5^{\prime}\right), 26.68\left(\mathrm{C}-2^{\prime}\right)$, 28.17 (C-3'), 31.38 (C-4'), 42.63 (C-1'), 101.24 (C-2), 114.07 (C-9), 118.71 (C-6), 122.14 (C-8), 133.58 (C-10), 137.67 (C-7), 147.73 (C-3), 161.66 (C-5), 182.18 (C=O), $186.11(\mathrm{C}=\mathrm{O})$; LC-MS (ESI , $m / z$ ) calculated for $\mathrm{C}_{16} \mathrm{H}_{19} \mathrm{NO}_{3}: 273.14$, found for $296.26\left[\mathrm{M}+\mathrm{Na}^{+}\right.$; HRMS-ESI: $\mathrm{m} / z$ calculated for $\mathrm{C}_{16} \mathrm{H}_{20} \mathrm{O} 3 \mathrm{~N}: 274.1438[\mathrm{M}+\mathrm{H}]^{+}$, found for 274.1433 .

2-Octylamino-5-hydroxy-1,4-naphthoquinone (15a). The reaction produced 15a in $14.1 \%$ as an orange red solid; mp $128.2-129.5^{\circ} \mathrm{C} .{ }^{1} \mathrm{H}-\mathrm{NMR}\left(500 \mathrm{MHz}, \mathrm{CDCl}_{3}\right) \delta_{\mathrm{H}} 0.87\left(\mathrm{t}, J=6.6 \mathrm{~Hz}, 3 \mathrm{H}, \mathrm{CH}_{3}\right), 1.26-1.29$ (m, 6H, H-5', H-6', H-7'), 1.36-1.39 (m, 4H, H-3', H-4'), 1.67 (p, J=7.3 Hz, 2H, H-2'), 3.16 (q, J=6.6 Hz, 2H, H-1'), 5.60 (s, 1H, H-3), 6.04 (bs, 1H, -NH), 7.22 (d, J=8.0 Hz, 1H, H-8), 7.44 (t, J=7.9 Hz, 1H, $\mathrm{H}-7), 7.57$ (d, $J=7.5 \mathrm{~Hz}, 1 \mathrm{H}, \mathrm{H}-6), 13.08(\mathrm{~s}, 1 \mathrm{H}, 5-\mathrm{OH}) ;{ }^{13} \mathrm{C}-\mathrm{NMR}\left(125 \mathrm{MHz}, \mathrm{CDCl}_{3}\right) \delta_{\mathrm{C}} 14.29$ $\left(\mathrm{CH}_{3}\right), 22.83\left({\left.\mathrm{C}-7^{\prime}\right),}_{27.22}\left(\mathrm{C}-2^{\prime}\right), 28.43\left(\mathrm{C}-3^{\prime}\right), 29.35\left(\mathrm{C}-4^{\prime}\right), 29.92\left(\mathrm{C}-5^{\prime}\right), 31.95\left(\mathrm{C}-6^{\prime}\right), 42.94\left(\mathrm{C}-1^{\prime}\right)\right.$, 99.80 (C-3), 115.20 (C-9), 119.25 (C-6), 126.18 (C-8), 130.70 (C-10), 134.04 (C-7), 148.88 (C-2), $161.33(\mathrm{C}-5), 181.42(\mathrm{C}=\mathrm{O}), 189.14(\mathrm{C}=\mathrm{O})$; LC-MS $\left(\mathrm{ESI}^{+}, \mathrm{m} / \mathrm{z}\right)$ calculated for $\mathrm{C}_{18} \mathrm{H}_{23} \mathrm{NO}_{3}: 301.17$, found for $324.34[\mathrm{M}+\mathrm{Na}]^{+}$; HRMS-ESI: $m / z$ calculated for $\mathrm{C}_{18} \mathrm{H}_{24} \mathrm{O}_{3} \mathrm{~N}$ : $302.1751[\mathrm{M}+\mathrm{H}]^{+}$, found for 302.1746 .

3-Octylamino-5-hydroxy-1,4-naphthoquinone (15b). The reaction produced $\mathbf{1 5 b}$ in $31.4 \%$ as an orange red solid; mp $119.5-120.3{ }^{\circ} \mathrm{C} .{ }^{1} \mathrm{H}-\mathrm{NMR}\left(500 \mathrm{MHz}, \mathrm{CDCl}_{3}\right) \delta_{\mathrm{H}} 0.87$ (t, $\left.J=6.3 \mathrm{~Hz}, 3 \mathrm{H}, \mathrm{CH}_{3}\right), 1.23-1.29$ (m, 6H, H-5', H-6', H-7'), 1.37-1.39 (m, 2H, H-4'), 1.65-1.70 (m, 4H, H-2', H-3'), 3.16 (q, J=6.4 Hz, 2H, H-1'), 5.70 (s, 1H, H-2), 5.87 (bs, 1H, -NH), 7.11 (d, J=7.3, 1H, H-8), 7.57-7.61 (m, 2H, H-6, H-7), $11.52(\mathrm{~s}, 1 \mathrm{H}, 5-\mathrm{OH}) ;{ }^{13} \mathrm{C}-\mathrm{NMR}\left(125 \mathrm{MHz}, \mathrm{CDCl}_{3}\right) \delta_{\mathrm{C}} 14.29\left(\mathrm{CH}_{3}\right), 22.84\left(\mathrm{C}-7^{\prime}\right), 27.24\left(\mathrm{C}-2^{\prime}\right), 28.45$ (C-3'), 29.36 (C-4'), 29.42 (C-5'), $31.96\left(\mathrm{C}-6^{\prime}\right), 42.90$ (C-1'), 101.46 (C-2), 114.31 (C-9), 118.98 (C-6), 122.40 (C-8), 133.81 (C-10), 137.93 (C-7), 148.02 (C-3), 161.93 (C-5), $182.40(\mathrm{C}=\mathrm{O}), 186.33(\mathrm{C}=\mathrm{O})$; LC-MS $\left(\mathrm{ESI}^{+}, m / z\right)$ calculated for $\mathrm{C}_{18} \mathrm{H}_{23} \mathrm{NO}_{3}: 301.17$, found for $324.36[\mathrm{M}+\mathrm{Na}]^{+}$; HRMS-ESI: $m / z$ calculated for $\mathrm{C}_{18} \mathrm{H}_{24} \mathrm{O} 3 \mathrm{~N}$ : $302.1751[\mathrm{M}+\mathrm{H}]^{+}$, found for 302.1749 .

2-Decylamino-5-hydroxy-1,4-naphthoquinone (16a). The reaction produced 16a in $19.2 \%$ as an orange red solid; mp $124.5-125.7{ }^{\circ} \mathrm{C} .{ }^{1} \mathrm{H}-\mathrm{NMR}\left(500 \mathrm{MHz}, \mathrm{CDCl}_{3}\right) \delta_{\mathrm{H}} 0.86\left(\mathrm{t}, J=6.8 \mathrm{~Hz}, 3 \mathrm{H}, \mathrm{CH}_{3}\right), 1.23-1.30$ 
(m, 8H, H-6', H-7', H-8', H-9'), 1.35-1.40 (m, 6H, H-3', H-4', H-5'), 1.67 (p, J= $7.3 \mathrm{~Hz}, 2 \mathrm{H}, \mathrm{H}-2^{\prime}$ ), 3.17 (q, $\left.J=6.7 \mathrm{~Hz}, 2 \mathrm{H}, \mathrm{H}-1^{\prime}\right), 5.61$ (s, 1H, H-3), 6.05 (bs, 1H, -NH), 7.22 (dd, $J=2.2,7.3 \mathrm{~Hz}, 1 \mathrm{H}, \mathrm{H}-8$ ), 7.44 (dt, 1H, $J=1.0,7.5 \mathrm{~Hz}, \mathrm{H}-7), 7.56$ (dd, 1H, $J=1.0,7.5 \mathrm{~Hz}, \mathrm{H}-6), 13.08$ (s, 1H, 5-OH); ${ }^{13} \mathrm{C}-\mathrm{NMR}$ (125 MHz, CDCl 3$) \delta_{\mathrm{C}} 14.09\left(\mathrm{CH}_{3}\right), 22.65\left(\mathrm{C}-9^{\prime}\right), 26.98\left(\mathrm{C}-2^{\prime}\right), 28.19\left(\mathrm{C}-3^{\prime}\right), 29.20\left(\mathrm{C}-4^{\prime}\right), 29.25\left(\mathrm{C}-5^{\prime}\right)$, 29.46 (C-6'), 29.47 (C-7'), 31.85 (C-8'), 42.71 (C-1'), 99.57 (C-3), 114.97 (C-9), 119.02 (C-6), 125.95 (C-8), 130.47 (C-10), 133.82 (C-7), 148.66 (C-2), 161.10 (C-5), 181.20 (C=O), 188.91 (C=O); LC-MS $\left(\mathrm{ESI}^{+}, m / z\right)$ calculated for $\mathrm{C}_{20} \mathrm{H}_{29} \mathrm{NO}_{3}: 329.20$, found for $352.47[\mathrm{M}+\mathrm{Na}]^{+}$; HRMS-ESI: $m / z$ calculated for $\mathrm{C}_{20} \mathrm{H}_{28} \mathrm{O} 3 \mathrm{~N}: 330.2064[\mathrm{M}+\mathrm{H}]^{+}$, found for 330.2058 .

3-Decylamino-5-hydroxy-1,4-naphthoquinone (16b). The reaction produced $\mathbf{1 6 b}$ in $39.5 \%$ as an orange red solid; mp 95.8-96.9 ${ }^{\circ} \mathrm{C}$. ${ }^{1} \mathrm{H}-\mathrm{NMR}\left(500 \mathrm{MHz}, \mathrm{CDCl}_{3}\right) \delta_{\mathrm{H}} 0.86\left(\mathrm{t}, J=6.8 \mathrm{~Hz}, 3 \mathrm{H}, \mathrm{CH}_{3}\right), 1.23-1.31$ (m, 10H, H-5', H-6', H-7', H-8', H-9'), 1.35-1.40 (m, 4H, H-3', H-4',), 1.67 (p, J = 7.3 Hz, 2H, H-2'), 3.16 (q, J=6.7 Hz, 2H, H-1'), 5.68 (s, 1H, H-2), 5.86 (bs, 1H, -NH), 7.11 (dd, J=2.2, 7.3 Hz, 1H, H-8), 7.57-7.61 (m, 2H, H-6, H-7), $11.51(\mathrm{~s}, 1 \mathrm{H}, 5-\mathrm{OH}) ;{ }^{13} \mathrm{C}-\mathrm{NMR}\left(125 \mathrm{MHz}, \mathrm{CDCl}_{3}\right) \delta_{\mathrm{C}} 14.32\left(\mathrm{CH}_{3}\right)$, 22.88 (C-9'), 27.24 (C-2'), 28.44 (C-3'), 29.45 (C-4'), 29.48 (C-5'), 29.70 (C-6'), 29.92 (C-7'), 32.08 (C-8'), 42.89 (C-1'), 101.45 (C-2), 114.30 (C-9), 118.97 (C-6), 122.39 (C-8), 133.80 (C-10), 137.91 (C-7), $148.02(\mathrm{C}-3), 161.92(\mathrm{C}-5), 182.38(\mathrm{C}=\mathrm{O}), 186.31(\mathrm{C}=\mathrm{O})$; LC-MS (ESI $\left.{ }^{+}, \mathrm{m} / z\right)$ calculated for $\mathrm{C}_{20} \mathrm{H}_{29} \mathrm{NO}_{3}: 329.20$, found for $330.26[\mathrm{M}+\mathrm{H}]^{+}$; HRMS-ESI: $m / z$ calculated for $\mathrm{C}_{20} \mathrm{H}_{28} \mathrm{O} 3 \mathrm{~N}: 330.2064$ $[\mathrm{M}+\mathrm{H}]^{+}$, found for 330.2059 .

2-Dodecylamino-5-hydroxy-1,4-naphthoquinone (17a). The reaction produced $\mathbf{1 7 a}$ in $15.5 \%$ as an orange red solid; mp 121.8-122.2 ${ }^{\circ} \mathrm{C} .{ }^{1} \mathrm{H}-\mathrm{NMR}\left(500 \mathrm{MHz}, \mathrm{CDCl}_{3}\right) \delta_{\mathrm{H}} 0.86\left(\mathrm{t}, J=6.8 \mathrm{~Hz}, 3 \mathrm{H}, \mathrm{CH}_{3}\right)$, 1.24-1.31 (m, 14H, H-5', H-6', H-7', H-8', H-9', H-10', H-11'), 1.34-1.40 (m, 4H, H-3', H-4'), 1.67 (p, $\left.J=7.3 \mathrm{~Hz}, 2 \mathrm{H}, \mathrm{H}-2^{\prime}\right), 3.16$ (q, $\left.J=6.6 \mathrm{~Hz}, 2 \mathrm{H}, \mathrm{H}-1^{\prime}\right), 5.60$ (s, 1H, H-3), 6.05 (bs, 1H, -NH), 7.22 (d, $J=8.4 \mathrm{~Hz}, 1 \mathrm{H}, \mathrm{H}-8), 7.44$ (t, 1H, $J=7.9 \mathrm{~Hz}, \mathrm{H}-7), 7.56$ (d, 1H, $J=7.5 \mathrm{~Hz}, \mathrm{H}-6), 13.08$ (s, 1H, 5-OH); ${ }^{13} \mathrm{C}-\mathrm{NMR}\left(125 \mathrm{MHz}, \mathrm{CDCl}_{3}\right) \delta_{\mathrm{C}} 14.34\left(\mathrm{CH}_{3}\right), 22.90\left(\mathrm{C}-11^{\prime}\right), 27.22\left(\mathrm{C}-2^{\prime}\right), 28.42\left(\mathrm{C}-3^{\prime}\right), 29.44\left(\mathrm{C}-4^{\prime}\right)$, 29.55 (C-5'), 29.69 (C-6'), 29.75 (C-7'), 29.83 (C-8'), 29.92 (C-9'), 32.12 (C-10'), 42.94 (C-1'), 99.80 (C-3), 115.20 (C-9), 119.25 (C-6), 126.18 (C-8), 130.70 (C-10), 134.04 (C-7), 148.88 (C-2), 161.33 (C-5), $181.42(\mathrm{C}=\mathrm{O}), 189.13(\mathrm{C}=\mathrm{O})$; LC-MS $\left(\mathrm{ESI}^{+}, \mathrm{m} / \mathrm{z}\right)$ calculated for $\mathrm{C}_{22} \mathrm{H}_{31} \mathrm{NO}_{3}$ : 357.23 , found for 380.44 $[\mathrm{M}+\mathrm{Na}]^{+}$; HRMS-ESI: $m / z$ calculated for $\mathrm{C}_{22} \mathrm{H}_{32} \mathrm{O}{ }_{3} \mathrm{~N}: 358.2377[\mathrm{M}+\mathrm{H}]^{+}$, found for 358.2371.

3-Dodecylamino-5-hydroxy-1,4-naphthoquinone (17b). The reaction produced $\mathbf{1 7 b}$ in $24.6 \%$ as an orange red solid; mp 98.0-98.5 ${ }^{\circ} \mathrm{C} .{ }^{1} \mathrm{H}-\mathrm{NMR}\left(500 \mathrm{MHz}, \mathrm{CDCl}_{3}\right) \delta_{\mathrm{H}} 0.86\left(\mathrm{t}, J=6.7 \mathrm{~Hz}, 3 \mathrm{H}, \mathrm{CH}_{3}\right)$, 1.24-1.31 (m, 12H, H-6', H-7', H-8', H-9', H-10', H-11'), 1.35-1.39 (m, 4H, H-4', H-5'), 1.65-1.70 (m, 4H, H-2', H-3'), 3.15 (t, $\left.J=6.1 \mathrm{~Hz}, 2 \mathrm{H}, \mathrm{H}-1^{\prime}\right), 5.70$ (s, 1H, H-2), 5.87 (bs, 1H, -NH), 7.11 (d, J = 7.4 Hz, 1H, H-8), 7.57-7.61 (m, 2H, H-6, H-7), 11.52 (s, 1H, 5-OH); ${ }^{13} \mathrm{C}-\mathrm{NMR}\left(125 \mathrm{MHz}, \mathrm{CDCl}_{3}\right) \delta_{\mathrm{C}} 14.34$ $\left(\mathrm{CH}_{3}\right), 22.90\left(\mathrm{C}-11^{\prime}\right), 27.24$ (C-2'), 28.44 (C-3'), 29.45 (C-4'), 29.55 (C-5), $29.70\left(\mathrm{C}-6^{\prime}\right), 29.76\left(\mathrm{C}-7^{\prime}\right), 29.83$ (C-8'), 29.92 (C-9'), 32.13 (C-10'), 42.87 (C-1'), 101.49 (C-2), 114.32 (C-9), 118.95 (C-6), 122.37 (C-8), 133.83 (C-10), 137.91 (C-7), 147.97 (C-3), 161.90 (C-5), 182.42 (C=O), 186.34 (C=O); LC-MS (ESI', $m / z$ ) calculated for $\mathrm{C}_{22} \mathrm{H}_{31} \mathrm{NO}_{3}: 357.23$, found for $380.46[\mathrm{M}+\mathrm{Na}]^{+}$; HRMS-ESI: $m / z$ calculated for $\mathrm{C}_{22} \mathrm{H}_{32} \mathrm{O} 3 \mathrm{~N}: 358.2377[\mathrm{M}+\mathrm{H}]^{+}$, found for 358.2374 . 
2-[(2-Aminoethyl)-morpholine]-5-hydroxy-1,4-naphthoquinone (18a). The reaction produced 18a in $38.9 \%$ as a red solid; mp $122.0-122.5{ }^{\circ} \mathrm{C} .{ }^{1} \mathrm{H}-\mathrm{NMR}\left(500 \mathrm{MHz}, \mathrm{CDCl}_{3}\right) \delta_{\mathrm{H}} 2.48$ (t, J=4.2 Hz, 4H, H-2", H-6"), 2.67 (t, $\left.J=6.0 \mathrm{~Hz}, 2 \mathrm{H}, \mathrm{H}-2^{\prime}\right), 3.22$ (q, $\left.J=5.7 \mathrm{~Hz}, 2 \mathrm{H}, \mathrm{H}-1^{\prime}\right), 3.72$ (t, $\left.J=4.6 \mathrm{~Hz}, 4 \mathrm{H}, \mathrm{H}-3^{\prime \prime}, \mathrm{H}-5^{\prime \prime}\right)$, 5.59 (s, 1H, H-3), 6.66 (bs, 1H, -NH), 7.22 (dd, $J=0.9,8.4 \mathrm{~Hz}, 1 \mathrm{H}, \mathrm{H}-8), 7.45$ (t, $J=7.9 \mathrm{~Hz}, 1 \mathrm{H}$, $\mathrm{H}-7), 7.57$ (dd, $J=0.9,7.2 \mathrm{~Hz}, 2 \mathrm{H}, \mathrm{H}-6), 13.05$ (s, 1H, 5-OH); ${ }^{13} \mathrm{C}-\mathrm{NMR}\left(125 \mathrm{MHz}, \mathrm{CDCl}_{3}\right) \delta_{\mathrm{c}} 38.68$ $\left(\mathrm{C}-1^{\prime}\right), 53.39$ (C-2", C-6"), 55.68 (C-2'), 67.10 (C-3", C-5"), 100.12 (C-2), 115.18 (C-9), 119.22 (C-6), 126.13 (C-8), 130.76 (C-10), 134.13 (C-7), 148.89 (C-3), 161.32 (C-5), 181.28 (C=O), 189.17 (C=O); LC-MS $\left(\mathrm{ESI}^{-}, \mathrm{m} / \mathrm{z}\right)$ calculated for $\mathrm{C}_{16} \mathrm{H}_{18} \mathrm{~N}_{2} \mathrm{O}_{4}: 302.13$, found for $301.08[\mathrm{M}-\mathrm{H}]^{-}$; HRMS-ESI: $m / z$ calculated for $\mathrm{C}_{16} \mathrm{H}_{18} \mathrm{~N}_{2} \mathrm{O}_{4}: 302.1267[\mathrm{M}]^{+}$, found for 302.1264 .

3-[(2-Aminoethyl)-morpholine]-5-hydroxy-1,4-naphthoquinone (18b). The reaction produced $\mathbf{1 8 b}$ in $16.8 \%$ as a red solid; mp 150.2-151.4 ${ }^{\circ} \mathrm{C} .{ }^{1} \mathrm{H}-\mathrm{NMR}\left(500 \mathrm{MHz}, \mathrm{CDCl}_{3}\right) \delta \mathrm{H} 2.49$ (t, $J=8.5 \mathrm{~Hz}, 4 \mathrm{H}$, H-2", H-6"), 2.69 (t, $\left.J=6.0 \mathrm{~Hz}, 2 \mathrm{H}, \mathrm{H}-2^{\prime}\right), 3.20$ (q, $\left.J=5.5 \mathrm{~Hz}, 2 \mathrm{H}, \mathrm{H}-1^{\prime}\right), 3.74$ (t, $J=5.0 \mathrm{~Hz}, 4 \mathrm{H}, \mathrm{H}-3^{\prime \prime}$, H-5"), 5.66 (s, 1H, H-3), 6.49 (bs, 1H, -NH), 7.12 (dd, $J=2.7,6.8 \mathrm{~Hz}, 1 \mathrm{H}, \mathrm{H}-8), 7.57-7.61$ (m, 2H, H-6, H-7), 11.56 (s, 1H, 5-OH); ${ }^{13} \mathrm{C}-\mathrm{NMR}\left(125 \mathrm{MHz}, \mathrm{CDCl}_{3}\right) \delta_{\mathrm{C}} 38.36$ (C-1'), 53.16 (C-2", C-6"), 55.49 (C-2'), 66.65 (C-3", C-5"), 99.97 (C-2), 114.94 (C-9), 119.05 (C-6), 125.92 (C-8), 130.55 (C-10), 133.96 (C-7), 148.65 (C-2), $161.11(\mathrm{C}-5), 181.01(\mathrm{C}=\mathrm{O}), 188.97(\mathrm{C}=\mathrm{O})$; LC-MS (ESI $\left.{ }^{-}, m / z\right)$ calculated for $\mathrm{C}_{16} \mathrm{H}_{18} \mathrm{~N}_{2} \mathrm{O}_{4}$ : 302.13, found for 301.16 [M $\left.-\mathrm{H}\right]^{-}$; HRMS-ESI: $m / z$ calculated for $\mathrm{C}_{16} \mathrm{H}_{18} \mathrm{~N}_{2} \mathrm{O}_{4}: 302.1267[\mathrm{M}]^{+}$, found for 302.1261 .

2-[(3-Aminopropyl)-morpholine]-5-hydroxy-1,4-naphthoquinone (19a). The reaction produced 19a in 29.2\% as a red solid; mp 84.5-85.6 ${ }^{\circ} \mathrm{C} .{ }^{1} \mathrm{H}-\mathrm{NMR}\left(500 \mathrm{MHz}, \mathrm{CDCl}_{3}\right) \delta_{\mathrm{H}} 1.84\left(\mathrm{p}, J=5.9 \mathrm{~Hz}, 2 \mathrm{H}, \mathrm{H}-2^{\prime}\right)$, 2.49 (bs, 4H, H-2", H-6"), 2.54 (t, $J=5.8$ Hz, 2H, H-3'), 3.27 (q, $J=5.7 \mathrm{~Hz}, 2 \mathrm{H}, \mathrm{H}-1^{\prime}$ ), 3.84 (t, $J=4.6 \mathrm{~Hz}$, 4H, H-3", H-5"), 5.55 (s, 1H, H-3), 7.20 (dd, $J=0.8,8.0 \mathrm{~Hz}, 1 \mathrm{H}, \mathrm{H}-8), 7.43$ (t, $J=7.9 \mathrm{~Hz}, 1 \mathrm{H}, \mathrm{H}-7$ ), $7.56(\mathrm{dd}, J=0.9,7.6 \mathrm{~Hz}, 1 \mathrm{H}, \mathrm{H}-6), 8.08$ (bs, 1H, -NH), 13.17 (s, 1H, 5-OH); ${ }^{13} \mathrm{C}-\mathrm{NMR}(125 \mathrm{MHz}$, $\left.\mathrm{CDCl}_{3}\right) \delta_{\mathrm{C}} 23.21\left(\mathrm{C}-2^{\prime}\right), 43.15\left(\mathrm{C}-1^{\prime}\right), 53.83\left(\mathrm{C}-2^{\prime \prime}, \mathrm{C}-6^{\prime \prime}\right), 57.91\left(\mathrm{C}-3^{\prime}\right), 66.76\left(\mathrm{C}-3^{\prime \prime}, \mathrm{C}-5^{\prime \prime}\right), 99.04(\mathrm{C}-2)$, 115.12 (C-9), 118.89 (C-6), 125.70 (C-8), 130.69 (C-10), 133.70 (C-7), 149.46 (C-3), 161.06 (C-5), $181.21(\mathrm{C}=\mathrm{O}), 188.84(\mathrm{C}=\mathrm{O})$; LC-MS $\left(\mathrm{ESI}^{-}, m / z\right)$ calculated for $\mathrm{C}_{17} \mathrm{H}_{20} \mathrm{~N}_{2} \mathrm{O}_{4}: 316.14$, found for 315.10 $[\mathrm{M}-\mathrm{H}]^{-}$; HRMS-ESI: $m / z$ calculated for $\mathrm{C}_{17} \mathrm{H}_{20} \mathrm{O}_{4} \mathrm{~N}_{2}: 316.1423[\mathrm{M}]^{+}$, found for 316.1428 .

2-[(3-Aminopropyl)-morpholine]-5-hydroxy-1,4-naphthoquinone (19b). The reaction produced 19b in $30.2 \%$ as a red solid; mp 101.6-102.7 ${ }^{\circ} \mathrm{C} .{ }^{1} \mathrm{H}-\mathrm{NMR}\left(500 \mathrm{MHz}, \mathrm{CDCl}_{3}\right) \delta_{\mathrm{H}} 1.84\left(\mathrm{p}, J=6.0 \mathrm{~Hz}, 2 \mathrm{H}, \mathrm{H}-2^{\prime}\right)$, 2.50 (bs, 4H, H-2", H-6"), 2.55 (t, $\left.J=5.8 \mathrm{~Hz}, 2 \mathrm{H}, \mathrm{H}-3^{\prime}\right), 3.25$ (q, $J=5.5 \mathrm{~Hz}, 2 \mathrm{H}, \mathrm{H}-1^{\prime}$ ), 3.84 (t, $J=4.6 \mathrm{~Hz}$, 4H, H-3", H-5"), 5.63 (s, 1H, H-3), 7.10 (dd, J=2.2, 7.3 Hz, 1H, H-8), 7.56-7.60 (m, 2H, H-6, H-7), 7.99 (bs, 1H, -NH), 11.63 (s, 1H, 5-OH); ${ }^{13} \mathrm{C}-\mathrm{NMR}\left(125 \mathrm{MHz}, \mathrm{CDCl}_{3}\right) \delta_{\mathrm{C}} 23.15\left(\mathrm{C}-2^{\prime}\right), 43.24\left(\mathrm{C}-1^{\prime}\right)$, 53.83 (C-2", C-6"), 58.05 (C-3'), 66.78 (C-3", C-5"), 100.77 (C-3), 114.22 (C-9), 118.60 (C-6), 122.05 (C-8), 133.76 (C-10), 137.55 (C-7), 148.55 (C-2), 161.69 (C-5), 182.17 (C=O), 186.51 (C=O); LC-MS $\left(\mathrm{ESI}^{-}, m / z\right)$ calculated for $\mathrm{C}_{17} \mathrm{H}_{20} \mathrm{~N}_{2} \mathrm{O}_{4}: 316.14$, found for $315.11[\mathrm{M}-\mathrm{H}]^{-}$; HRMS-ESI: $m / z$ calculated for $\mathrm{C}_{17} \mathrm{H}_{20} \mathrm{O}_{4} \mathrm{~N}_{2}: 316.1423[\mathrm{M}]^{+}$, found for 316.1428 . 


\subsection{Biological Activity}

\subsubsection{Cell Lines and Cell Culture Conditions}

All cells were obtained from the Bioresource Collection and Research Center (Hsinchu, Taiwan). Human colorectal adenocarcinoma cells (HT-29) and human promyelocytic leukemia cells (HL-60) cells were cultured in RPMI 1640 (HyClone, Logan, USA) medium, supplemented with 10\% fetal bovine serum (FBS, Gibco, Life Technologies, New York, NY, USA) and antibiotics (100 $\mu \mathrm{g} / \mathrm{mL}$ streptomycin and 100 units/mL penicillin, Gibco, Life Technologies). Human colorectal adenocarcinoma cells (SW480), human breast adenocarcinoma cells (MCF-7), human hepatocellular carcinoma cells (HepG2), and normal murine embryonic liver cells (BNL CL.2) were cultured in Dulbecco's modified Eagle's medium (DMEM, HyClone, Logan, USA), supplemented with 10\% fetal bovine serum (FBS) and antibiotics. Human cancer cells were maintained in humidified atmosphere with $5 \% \mathrm{CO}_{2}$ and $95 \%$ air at $37{ }^{\circ} \mathrm{C}$ in a carbon dioxide incubator (SANYO, $\mathrm{CO}_{2}$ incubator, Osaka, Japan).

\subsubsection{Cell Viability Assay}

The cytotoxic effect of 34 1,4-naphthoquinone derivatives on five human cancer cell lines was measured by 3-(4,5-dimethylthiazol-2-yl)-2,5-diphenyl tetrazolium bromide (MTT, Bionovas Biotechnology Co., Ltd., Toronto, ON, Canada) as described by Mosmann [26]. The MTT assay depends on the mitochondrial enzyme reduction of tetrazolium dye to detect and determine cell viability. Briefly, the cancer cells or normal cells were plated at $5 \times 10^{3}-1 \times 10^{4}$ cells into 96-well plates and HL-60 cells were plated at $1 \times 10^{5}$ cells $/ \mathrm{mL}$ into 12 -well plates. After overnight growth, cells were treated with various concentrations of 1,4-naphthoquinone derivatives for $24 \mathrm{~h}, 48 \mathrm{~h}$ and $72 \mathrm{~h}$. At the end of treatment, final concentration of $0.5 \mathrm{mg} / \mathrm{mL}$ MTT was added, and the cells were incubated for a further $1.5 \mathrm{~h}$. The absorbance was recorded on an ELISA plate reader (SpectraMax 340 $\mathrm{PC}^{384}$, Molecular Devices, Sunnyvale, CA, USA) at $540 \mathrm{~nm}$. Cell viability was determined as the test compound concentration required to inhibit tumor cell proliferation by 50\% ( $\mathrm{IC}_{50}$ ) from the dose-response curves. All data are reported as average values from triplicate samples and the experiments were repeated at least three times.

\subsubsection{Nuclear Staining with Hoechst 33258}

HT-29 cells were plate at $7 \times 10^{5}$ cells per $6-\mathrm{cm}$ dish. After overnight, cells were treated with 0.5-2.5 $\mu \mathrm{M}$ plumbagin (1) and 11a for $48 \mathrm{~h}$. The cells of each dish were stained with $5 \mathrm{mM}$ Hoechst 33258 (Sigma-Aldrich, St. Louis, MO, USA). After the cells were incubated in a dark room for 5 min, the cells were washed with PBS and then were observed using a fluorescent microscope (Zeiss, Axio Observer A1, Göttingen, Germany).

\subsubsection{Cell Cycle Distribution Analysis}

HT-29 cells were plated at a $1 \times 10^{6}$ cells per 6 -cm dish and cultured overnight. Then various concentration of 0.5-2.5 $\mu \mathrm{M}$ plumbagin (1) and 11a were added for $48 \mathrm{~h}$. The cells of each dish were harvested, then washed once with PBS and fixed with methanol at $4{ }^{\circ} \mathrm{C}$. After $18 \mathrm{~h}$, the cells of each dish were harvested, washed once with PBS. The cells were resuspended in $473 \mu \mathrm{L}$ of PBS containing 
$40 \mu \mathrm{g} / \mathrm{mL}$ propidium iodide (PI) and $40 \mu \mathrm{g} / \mathrm{mL}$ RNase. Cells were incubated in a dark room for $30 \mathrm{~min}$ at room temperature then subjected to cell cycle analysis using a FACScan flow cytometer (Becton Dickinson, San Jose, CA, USA) and analyzed using the ModFit 3.0 software (Verity Software House, Topsham, ME, USA, 2008).

\subsubsection{Assessment of Apoptotic Analysis}

HT-29 cells were plated at a concentration of $1 \times 10^{6}$ cells per $6-\mathrm{cm}$ dish. After overnight growth, cells were treated with $0.5-2.5 \mu \mathrm{M}$ plumbagin (1) and 11a for $48 \mathrm{~h}$. The cells of each dish were harvested, then washed once with PBS. The cells were resuspended in $500 \mu \mathrm{L}$ of PBS containing $4 \mu \mathrm{g} / \mathrm{mL}$ PI and $4 \mu \mathrm{g} / \mathrm{mL}$ Annexin-V-FITC (apoptosis detection kit; R \& D Systems, Taipei, Taiwan). Cells were incubated in a dark room for $30 \mathrm{~min}$ at room temperature then subjected to cell cycle analysis using a FACScan flow cytometer (Becton Dickinson, San Jose, CA, USA). Annexin V-FITC and PI emission were detected in the FL1 and FL2 channels of the flow cytometer, respectively. Flow cytometer data showed three distinct populations of HT-29 cells. The normal healthy cells, early apoptotic, late apoptotic, and necrosis cells were represented by the Annexin V-negative/PI-negative population, Annexin V-positive/PI-negative, Annexin V-positive/PI-positive, and Annexin V-negative/PI-positive cells, respectively. The data were analyzed using a FACScan flow cytometer (Becton Dickinson, San Jose, CA, USA) requipped with ModFit 3.0 software (Verity Software House, Topsham, ME, USA).

\subsubsection{Statistical Analysis}

The values shown are the mean $\pm \mathrm{SD}$ of three independent experiments. Data are statistically evaluated by the Student's test from SigmaPlot 11.0 (Systat Software Inc., San Jose, CA, USA) and shown as significantly different when $* p<0.05, * * p<0.01$ and $* * * p<0.001$.

\section{Conclusions}

In summary, we have synthesized a series of 2-position and 3-position lipophilic substituted lawsone and juglone derivatives and shown their enhanced their anti-cancer activity. Among these compounds, a lawsone derivative 11a showed a superior cytotoxicity to all others. Furthermore, 11a has better cytotoxicity against human colorectal adenocarcinoma HT-29 cells, over other cell lines, with an $\mathrm{IC}_{50}$ value of $1.99 \pm 0.04 \mu \mathrm{M}$ for $48 \mathrm{~h}$. Cell cycle distribution and apoptotic analysis by flow cytometry indicated that $\mathbf{1 1 a}$ was arrested cell cycle in S phase and induced apoptosis in HT-29. The Hoechst 33258 staining study showed the nuclear condensation of apoptotic with 11a treatment. Furthermore, compound 11a has markedly induced apoptotic morphological changes and nuclear DNA fragmentation. The mechanism of cell growth inhibition of the compound remains the target of future investigations.

\section{Supplementary Materials}

Supplementary materials can be accessed at: http:/www.mdpi.com/1420-3049/20/07/11994/s1. 


\section{Acknowledgments}

Gratitude is extended to Christopher Liu for his valuable editorial revision. This study is supported by grants V101E2-001 and V103E2-002 from the Taipei Veterans General Hospital, Taiwan.

\section{Author Contributions}

Shao-Hung Wang suggested the research work and discussed the experimental data; Chih-Yu Lo determined and analyzed the LC-MS data of all compounds; Zhong-Heng Gwo and Hong-Jhih Lin finalized the experimental work, interpreted the results, and prepared tables and figures; Lih-Geeng Chen designed the research and discussed the results; Jin-Yi Wu and Cheng-Deng Kuo wrote the paper, edited and revised manuscript. All authors read and approved the final manuscript.

\section{Conflicts of Interest}

The authors declare no conflict of interest.

\section{References}

1. WHO Report. Available online: http://www.who.int/mediacentre/factsheets/fs297/en/index.html (accessed on 25 June 2015).

2. Jemal, A.; Bray, F.; Center, M.M.; Ferlay, J.; Ward, E.; Forman, D. Global cancer statistics. CA Cancer J. Clin. 2011, 61, 69-90.

3. Prasad, K.R.; Babu, K.S.; Rao, R.R.; Suresh, G.; Rekha, K.; Murthy, J.M.; Rani, P.U.; Rao, J.M. Synthesis and insect antifeedant activity of plumbagin derivatives. Med. Chem. Res. 2012, 21, 578-583.

4. Cowan, M.M. Plant products as antimicrobial agents. Clin. Microbiol. Rev. 1999, 12, 564-582.

5. Yang, J.T.; Li, Z.L.; Wu, J.Y.; Lu, F.J.; Chen, C.H. An oxidative stress mechanism of shikonin in human glioma cells. PLoS ONE 2014, 9, e94180.

6. McBride, T.J.; Oleson, J.J.; Woolf, D. The activity of streptonigrin against the Rauscher murine leukemia virus in vivo. Cancer Res. 1966, 26, 727-732.

7. Keyes, S.R.; Loomis, R.; di Giovanna, M.P.; Pritsos, C.A.; Rockwell, S.; Sartorelli, A.C. Cytotoxicity and DNA crosslinks produced by mitomycin analogs in aerobic and hypoxic EMT6 cells. Cancer Commun. 1991, 3, 351-356.

8. Reich, E.; Goldberg, I.H.; Rabinowitz, M. Structure-activity correlations of actinomycins and their derivatives. Nature 1962, 196, 743-748.

9. Atamanyuk, D.; Zimenkovsky, B.; Atamanyuk, V.; Nektegayev, I.; Lesyk, R. Synthesis and biological activity of new thiopyrano[2,3- $d]$ thiazoles containing a naphthoquinone moiety. Sci. Pharm. 2013, 81, 423-436.

10. Bhasin, D.; Etter, J.P.; Chettiar, S.N.; Mok, M.; Li, P.K. Antiproliferative activities and SAR studies of substituted anthraquinones and 1,4-naphthoquinones. Bioorg. Med. Chem. Lett. 2013, 23, 6864-6867.

11. Didry, N.; Dubrevil, L.; Pinkas, M. Activity of anthraquinonic and naphthoquinonic compounds on oral bacteria. Pharmazie 1994, 49, 681-683. 
12. Likhitwitayawuid, K.; Kaewamatawong, R.; Ruangrungsi, N.; Krungkrai, J. Antimalarial naphthaquinones from Nepenthes thorelii. Planta Med. 1998, 64, 237-241.

13. Mathew, N.; Paily, K.P.; Abidha; Vanamali, P.; Kalyanasundaram, M.; Balaraman, K. Macrofilaricidal activity of the plant Plumbago indica/rosea in vitro. Drug Dev. Res. 2002, 56, 33-39.

14. Kayser, O.; Kiderlen, A.F.; Laatsch, H.; Croft, S.L. In vitro leishmanicidal activity of monomeric and dimeric naphthoquinones. Acta Trop. 2000, 76, 131-138.

15. Nguyen, A.T.; Malonne, H.; Duez, P.; Vanhaelen-Fastre, R.; Vanhaelen, M.; Fontaine, J. Cytotoxic constituents from Plumbago zeylanica. Fitoterapia 2004, 75, 500-504.

16. Luo, P.; Wong, Y.F.; Ge, L.; Zhang, Z.F.; Liu, Y.; Liu, L.; Zhou, H. Anti-inflammatory and analgesic effect of plumbagin through inhibition of nuclear factor- $\kappa \mathrm{B}$ activation. J. Pharmacol. Exp. Ther. 2010, 335, 735-742.

17. Thomson, R.H. Naturally Occurring Quinones, IV. Recent Advances; Blackie Academic \& Professional: London, UK, 1997.

18. Eldhose, B.; Gunawan, M.; Rahman, M.; Latha, M.S.; Notario, V. Plumbagin reduces human colon cancer cell survival by inducing cell cycle arrest and mitochondria-mediated apoptosis. Int. J. Oncol. 2014, 45, 1913-1920.

19. Subramaniya, B.R.; Srinivasan, G.; Sadullah, S.S.; Davis, N.; Subhadara, L.B.; Halagowder, D.; Sivasitambaram, N.D. Apoptosis inducing effect of plumbagin on colonic cancer cells depends on expression of COX-2. PLOS ONE 2011, 6, e18695.

20. Pertino, M.W.; Theoduloz, C.; Palenzuela, J.A.; Afonso M.M.; Yesilada, E.; Monsalve, F.; González, P.; Droguett, D.; Schmeda-Hirschmann, G. Synthesis and pharmacological activity of diterpenylnaphthoquinone derivatives. Molecules 2011, 16, 8614-8628.

21. Del Corral, J.M.M.; Castro, M.A.; Gordaliza, M.; Martín, M.L.; Gualberto, S.A.; Gamito, A.M.; Cuevas, C.; San Feliciano, A. Synthesis and cytotoxicity of new aminoterpenylquinones. Bioorg. Med. Chem. 2005, 13, 631-644.

22. Kawamura, M.; Kuriyama, I.; Maruo, S.; Kuramochi, K.; Tsubaki, K.; Yoshida, H.; Mizushina, Y. Anti-tumor effects of novel 5-O-acyl plumbagins based on the inhibition of mammalian DNA replicative polymerase activity. PLOS ONE 2014, 9, e88736.

23. Kuo, S.C.; Ibuka, T.; Huang, L.J.; Lien, J.C.; Yean, S.R.; Huang, S.C.; Lednicer, D.; Morris-Natschke, S.; Lee, K.H. Synthesis and cytotoxicity of 1,2-disubstituted naphth[2,3-d] imidazole-4,9-diones and related compounds. J. Med. Chem. 1996, 39, 1447-1451.

24. Bonifazi, E.L.; Ríos-Luci, C.; León, L.G.; Burton, G.; Padrón, J.M.; Misico, R.I. Antiproliferative activity of synthetic naphthoquinones related to lapachol. First synthesis of 5-hydroxylapachol. Bioorg. Med. Chem. 2010, 18, 2621-2630.

25. Bhasin, D.; Chettiar, S.N.; Etter, J.P.; Mok, M.; Li, P.K. Anticancer activity and SAR studies of substituted 1,4-naphthoquinones. Bioorg. Med. Chem. 2013, 21, 4662-4669.

26. Mosmann, T. Rapid colorimetric assay for cellular growth and survival: application to proliferation and cytotoxicity assays. J. Immunol. Methods 1983, 65, 55-63.

27. Lo, C.Y.; Hsu, L.C.; Chen, M.S.; Lin, Y.J.; Chen, L.G.; Kuo, C.D.; Wu, J.Y. Synthesis and anticancer activity of a novel series of 9-O-substituted berberine derivatives: A lipophilic substitute role. Bioorg. Med. Chem. Lett. 2013, 23, 305-309. 
28. Mallavadhani, U.V.; Prasad, C.V.; Shrivastava, S.; Naidu, V.G. Synthesis and anticancer activity of some novel 5,6-fused hybrids of juglone based 1,4-naphthoquinones. Eur. J. Med. Chem. 2014, 83, 84-91.

29. Wu, J.Y.; Kuo, C.D.; Chu, C.Y.; Chen, M.S.; Lin, J.H.; Chen, Y.J.; Liao, H.F. Synthesis of novel lipophilic $N$-substituted norcantharimide derivatives and evaluation of their anticancer activities. Molecules 2014, 19, 6911-6928.

30. Hadjila, D.; Mohamed, H. Activated zeolites and heteropolyacids: An efficient catalysts for the synthesis of triacetoxyaromatic precursors of hydroxyquinones. Asian J. Chem. 2013, 25, 6112-6116.

31. Ishiguro, K.; Ohira, Y.; Oku, H. Antipruritic Dinaphthofuran-7,12-dione Derivatives from the Pericarp of Impatiens balsamina. J. Nat. Prod. 1998, 61, 1126-1129.

32. Bieber, L.W.; Rolim Neto, P.J.; Generino, R.M. Regioselective alkylation of substituted quinones by trialkylboranes. Tetrahedron Lett. 1999, 40, 4473-4476.

33. Lien, J.C.; Huang, L.J.; Teng, C.M.; Wang, J.P.; Kuo, S.C. Synthesis of 2-alkoxy 1,4-naphthoquinone derivatives as antiplatelet, antiinflammatory, and antiallergic agents. Chem. Pharm. Bull. 2002, 50, 672-674.

34. Fieser, L.F.; Naphthoquinone Antimalarials. IV-XI. Synthesis. J. Am. Chem. Soc. 1948, 70, 3174-3215.

35. Fugitt, R.B.; Schwing, G.W. Miticidal Ethers. US Patent 4,110,473, 29 August 1978.

36. Kishore, N.; Mishra, B.B.; Tiwari, V.K.; Tripathi, V. Difuranonaphthoquinones from Plumbago zeylanica roots. Phytochem. Lett. 2010, 3, 62-65.

37. Inoue, K.; Ueda, S.; Nayeshiro, H.; Moritome, N.; Inouye, H. Biosynthesis of naphthoquinones and anthraquinones in Streptocarpus dunnii cell cultures. Phytochemistry 1984, 23, 313-318.

38. Fiorito, S.; Epifano, F.; Bruyere, C.; Mathieu, V.; Kiss, R.; Genovese, S. Growth inhibitory activity for cancer cell lines of lapachol and its natural and semi-synthetic derivatives. Bioorg. Med. Chem. Lett. 2014, 24, 454-457.

39. Gebauer, M. Synthesis and structure-activity relationships of novel warfarin derivatives. Bioorg. Med. Chem. 2007, 15, 2414-2420.

40. Yavorskyy, A.; Shvydkiv, O.; Limburg, C.; Nolan, K.; Delauré, Y.M.C.; Oelgemöller, M. Photooxygenations in a bubble column reactor. Green Chem. 2012, 14, 888-892.

41. Bukhtoyarova, A.D.; Rybalova, T.V.; Ektova, L.V. Amination of 5-hydroxy-1,4-naphthoquinone in the presence of copper acetate. Russ. J. Org. Chem. 2010, 46, 855-859.

Sample Availability: Samples of the compounds 3, 5a,b-11a,b and 13a,b-19a,b are available from the authors.

(C) 2015 by the authors; licensee MDPI, Basel, Switzerland. This article is an open access article distributed under the terms and conditions of the Creative Commons Attribution license (http://creativecommons.org/licenses/by/4.0/). 